\title{
Inducing Visibility and Visual Deduction
}

\author{
Mary S. Morgan, LSE
}

February, 2020 


\title{
Inducing Visibility and Visual Deduction*
}

\author{
Mary S. Morgan
}

Keywords: diagrammatic reasoning; visual inference; visual deduction; graphical methods

\begin{abstract}
Scientists use diagrams not just to visualize objects and relations in their fields, both empirical and theoretical, but to reason with them as tools of their science. While the two dimensional space of diagrams might seem restrictive, scientific diagrams can depict many more than two elements, can be used to visualise the same materials in myriad different ways, and can be constructed in a considerable variety of forms. This paper takes up two generic puzzles about 2D visualizations. First: How do scientists in different communities use $2 \mathrm{D}$ spaces to depict materials which are not fundamentally spatial? This prompts the distinction between diagrams that operate in different kinds of spaces: 'real', 'ideal', and 'artificial'. And second: How do diagrams, in these different usages of $2 \mathrm{D}$ space, support various kinds of visual reasoning that cross over between inductive and deductive? The argument links the representational form and content of a diagram (its vocabulary and grammar) with the kinds of inferential and manipulative reasoning that are afforded, and constrained, by scientists' different usages of $2 \mathrm{D}$ space.
\end{abstract}

\section{Introduction}

Studies of how diagrams are used by scientists have established that such representations offer a potentially wide range of epistemological services that cross over from inductive to deductive work. But having recognised that diagrams offer a technology of representation that supports many different reasoning functions, it is critical to ask exactly what do the characteristic aspects

\footnotetext{
* My thanks go to Hsiang-Ke Chao, Harro Maas, Marcel Boumans and James Nguyen for engaging with the detail of my arguments; to participants at: a workshop on visualization convened by Erna Fiorentini in Berlin in 2014; a Taiwan conference on diagrams convened by Hsiang-Ke Chao in 2016, and the All-London HPS Reading Group's discussion of scientific diagrams in 2019 convened by Chiara Ambrosio. I also thank Xizi Luo for research assistance with the figures and two anonymous referees for the paper, whose challenging invitations for me to clarify proved incredibly helpful.
} 
of diagrams - especially their use of $2 \mathrm{D}$ space, as opposed to other $2 \mathrm{D}$ visual materials such as pictures or photos (or even other forms of representation such as in words or mathematics) - offer to the scientist? And how do diagrammatic representations that inhabit $2-\mathrm{D}$ space support such varied usages?

For the arguments of this paper, diagrams are taken to be both scientific objects that depict or denote things in the scientific field and - at the same time - tools used in scientists' work. ${ }^{1}$ The question to be explored concerns the importance of the specific form of diagrammatic representation to the modes of argument used with it. In Morgan (2012), I argued that making a model gives form to ideas in a particular medium of expression and in doing so makes them subject to a particular mode of reasoning that goes along with that medium. For example, a working hydraulic model has a different form, and involves a different mode of reasoning, to a model of the same system in algebraic form. Even though not all diagrams are models (just as not all models are diagrams), I suggest that the same principle applies to diagrams: and since diagrams take lots of different forms, those forms don't necessarily share one kind of usage or reasoning. So, here, I extend my analysis of the relationship between form and reasoning to a discussion of diagrams, especially investigating those diagrams that feature in inductive and deductive modes of science.

I use the labels 'inductive' and 'deductive' loosely here, for in the context of how scientists work with diagrams - I regard these both as explorative modes of

\footnotetext{
${ }^{1}$ I have drawn, in the analysis of this paper, especially on the papers and introductions of two journal special issue investigations into diagrams. Priest, de Toffoli and Findlen's introduction (2018) offers a succinct entrance into the history of science literature, range of claims, and some useful exemplars. They argue that one should think of diagrams as "closer to being things than representations of things", though from the practising scientist and so the view of this paper, they surely are both. Blackwell (2001), introducing another special issue in AI that offers particular resources for this paper, wants to treat diagrams as objects rather than as tools but again here - in usage, such objects can be tools. The work of three other scholars has also been important for my thinking. Klein's (1995) analysis of nineteenth-century terminology of diagramming as a 'method' captures both the making and using of diagrams. Boumans (2016) arguments about inductive judgement, and Woody's analyses of the practices of theorizing the periodic law in chemistry (2014) and of reasoning with molecular orbital diagrams (2000), all proved liberating for approaching the mixed nature of reasoning with diagrams.
} 
reasoning. Scientists use diagrams to investigate, analyse, explore, suggest or rule out hypotheses, and generally reason about both empirical and theoretical matters and materials. These reasoning practices, and functional usages, found with diagrams might not be strictly described as deductive or inductive, as recent history and philosophy of science discussions on the use of diagrams make clear. This difficulty can be seen from two perspectives: either scientists' reasoning practices do not always fit easily into these philosophical labels, or, philosophers' labels don't always organise scientists' modes of practical reasoning so well as philosophers might hope - as Woody (2014) deftly demonstrates in her analysis of the scientists' reasoning that went along with representations of the periodic law and periodic table. So, when I appeal to inductive and deductive modes of reasoning, these need to be loosely not strictly interpreted, not because the scientists are loose thinkers, but because practices are rarely so cut and dried. The point of this paper then is to concentrate attention not just on the diagrams of science per se, but on how scientists do science with them. Within this, I have organised my analysis to understand how diagrams serve to make things visible, and - separately - how visualizations work as a tool for reasoning; the claim here is that using diagrams involves processes of both 'inducing visibility' and of 'visual deduction'. ${ }^{2}$

Another preliminary difficulty is defining what counts as a diagram, and it is important to note from the start that this paper is not about visual images used in science in general, but about diagrams, a subset of visual images in which scientists construct depictions of their materials. Even amongst accounts of diagrams, a variety of ideas are relevant. James Elkins (1999) differentiates pictures and notation from 'schemata' - a generic category that includes diagrams - and defines this generic category by what is not included rather than what is. Sybille Krämer (2016) refers to 'scripts' or possibly "inscriptions", a

\footnotetext{
2 This paper therefore takes up the contrasting agenda (set historically for economics by Chao and Maas, 2017) into a broader analysis of diagrams in inductive and deductive usage. Some readers may consider these labels misleading, and might prefer other terms or modes of reasoning - such as abduction.
} 
category that "includes tables, lists, diagrams, graphs, and maps" (p205). Alan Blackwell (2001) treats diagrams as objects that are not pictures or words. Perini's (2013) account reaches closest to my interests in fixing interest on how "spatial relations in the picture are interpreted and thus convey content" (p 274). Her notion of diagrams includes pictures, but the critical point for me is how she focusses attention on the 'form-content relations' of diagrams in the context of visual representations in biology.

The extensive $\mathrm{OED}^{3}$ definitions of diagrams refer to "An illustrative figure which, without representing the exact appearance of an object, gives an outline or general scheme of it, so as to exhibit the shape and relations of its various parts." Another OED definition points out that diagrammatic representations of empirical materials are essentially symbolic in form: "a set of lines, marks, or tracings which represent symbolically the course of results of any action or processes, or the variations which characterize it”. Useful for deductive reasoning, they point to a definition coming from geometry: "a figure composed of lines, serving to illustrate a definition or statement, or to aid in the proof of a proposition". And finally, another definition captures way that diagrams are sometimes used to depict abstract or conceptual or imagined things: "A delineation used to symbolize related abstract propositions or mental processes".

All of these definitions prove relevant to the examples I discuss here. However, my aim is not to be driven by the definitions, nor to what is or is not a diagram in the sciences, but to point to how these definitions, taken together, offer possibilities for understanding the forms of diagrams, and their associated reasoning resources. This focus on the use of diagrams in various modes is designed to throw light on how different modes of reasoning with diagrams

\footnotetext{
${ }^{3}$ OED online consulted 13 ${ }^{\text {th }}$ August, 2018: http://www.oed.com/view/Entry/51854 
depend on their form of construction, modes which are typically shared within a community of users in their research activities. ${ }^{4}$

\section{Inducing Visibility}

Inducing visibility is an apt phrase, due to Erna Fiorentini, to refer to the ways in which producing diagrams makes things visible that were not visible before. ${ }^{5}$ These diagramming processes are often (but surely not always) associated with the evidential space, and the process of inducing sense out of a collection of bits and pieces that are not so obviously related or not previously understood to be so. These processes might be broken down, in abstract terms if not in practise, to involve two elements: cognitive and inferential.

First the cognitive aspect - by which I mean the ability to see something, or to recognise something, in the visual display a scientist produces that had lain unseen, un-remarked, or unrecognised in their other representing media such as tables, words, photos, summarising statistics, etc. (Of course there are images which are the result of specially designed revealing technologies in science - such as X-rays - but it would seem very odd to count these as 'diagrams', given the constructive connotations of that label found in the OED definitions and in the literature on diagrams in science studies more generally.) The second aspect is the ability to induce, or infer, within these diagrammized materials, which relies not only on salient subject matter knowledge, but more especially on the mode of reasoning appropriate to these diagrams. The problematic issue of inference beyond the diagram, back to the world, will be taken up later.

\footnotetext{
${ }^{4}$ I have discussed many of the examples and some of the ideas in this paper in various ways before, but there is a certain advantage in rethinking known objects of study (some of which go back to my first book) in the light of serious questions about how diagrams work. I hope readers will forgive the re-use of old examples in the service of this renewed enquiry.

5 This useful terminology was introduce at a meeting convened by Erna Fiorentini on "visualization" in Berlin in April 2014.
} 


\subsection{On Diagrams (not Tables) and Seeing (not Reading)}

The practical line between inducing visibility and inferring is necessarily opaque, for even the recognition of a pattern is itself an inference of a kind. So the examples offered here serve not so much to define the difference between inducing visibility and inferring by using diagrams, but to delineate what is associated with each aspect. Thus Figure 1 captures the moment that a scientist figured out that a drawn line - a graphic - made visible something quite difficult to see in a table of numbers. In Figure 1, we see something that is halfdiagrammatic, half tabular in form, an in-between object which reveals a nonregular, but definitely cyclical, pattern. The scientist, Clement Juglar, was a physician turned statistician/demographer, and his table-graphic captures the rises and falls in forms of money circulating in the economy in an indicative line beside the numbers. Figure 2 ( $(a$ and $b$ ) provides the contrast, demonstrating directly how a diagram (the graph, $\underline{\mathbf{2 b}}$ ) reveals, or enables the scientist to see possible relations between the marriage rate and the trade of the UK that lie hidden in the table of numbers (2a). In this diagram: time is envisioned to move horizontally to the right and the vertical axes give the scales for the two series of numbers; whereas in the associated table: time changes vertically downwards. ${ }^{6}$ So, not only did the language of representation move from numbers to diagrammed lines, but the mode of organisation and conventions of usage changed as the representation moved from tables to graphic diagrams.

\footnotetext{
${ }^{6}$ In our contemporary social science and public usage, a table is normally read downwards with time, which may account for the fact that when social scientists began to adopt graphs as a mode of representation for phenomena in historical time around the third quarter of the nineteenth century, time was often on the vertical axis. Conventions here were only settled in the last quarter of the nineteenth century within a history of serious discussion of such methods (see Maas and Morgan 2002). The convention that historical time is visualised left to right on an historical graph may be associated with direction of text reading; there is some evidence that in societies where text is read right to left, it seems more natural to read time in that direction too (see Tversky, 2004). On the other hand, other conventions reign in other fields. Geological strata maps depict geological (historical) time going vertically upwards. Sheredos et al (2013) provide examples of biological graphs in which time is on both axes (eg vertical is time of day, and horizontal on successive days). The seminal study of the history and development of timeseries graphs across the sciences is Klein, 1997
} 
Figure 1 Juglar's Table-Graph. He depicts, in a table with a sketched graph beside it, the circulation of money and credit cycles in and out of the Banque of France over the $19^{\text {th }}$ century.
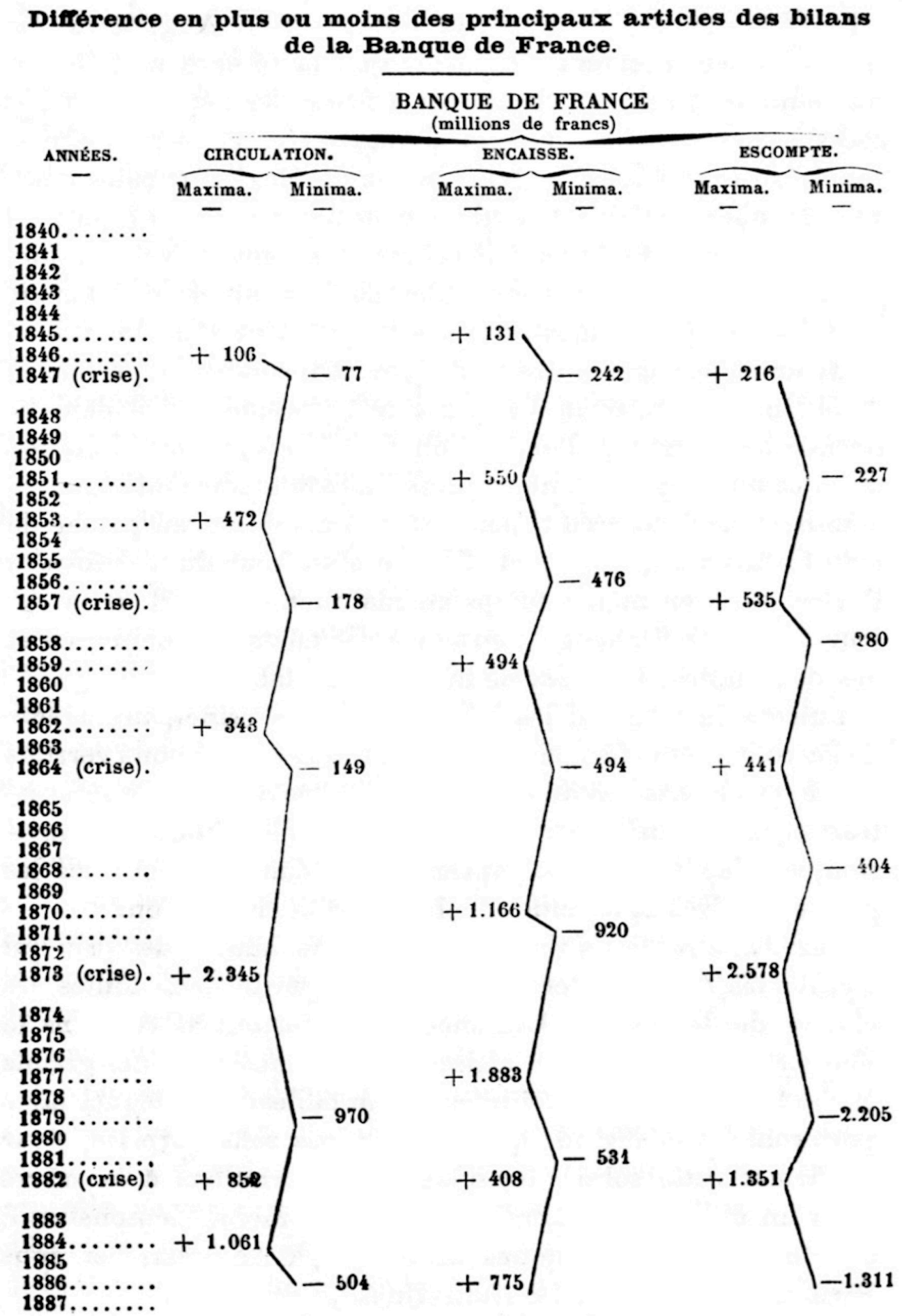

Source: Clement Juglar. 1862. Des Crises Commerciales edt de leur Terour Périodiqueen France, en Angleterre et aux État-Unis. 2 ${ }^{\text {nd }}$ Edition, 1889. p154. Paris: Guillaumin. 
Figure 2 Bowley's Development of Tables to Graphs. He converts the Table (a) of the marriage rate and trade into Graph (b) (his figure I) and then makes their relationship visible in another Graph (c) (his figure III).

(a)

Marriage Rate, Total Exports and Imports per Head of Popu lation, and Average Price of Wheat per Quarter.

\begin{tabular}{|c|c|c|c|}
\hline Year. & $\begin{array}{c}\text { Marriage } \\
\text { Rate. }\end{array}$ & $\begin{array}{l}\text { Total Exports } \\
\text { and Imports } \\
\text { per Head. }\end{array}$ & $\begin{array}{l}\text { Average Price } \\
\text { of Wheat } \\
\text { per Quarter. }\end{array}$ \\
\hline $\begin{array}{l}1860 \\
1861 \\
1862 \\
1863 \\
1864 \\
1865 \\
1866 \\
1867 \\
1868 \\
1869 \\
1870 \\
1871 \\
1872 \\
1873 \\
1874 \\
1875 \\
1876 \\
1877 \\
1878 \\
1879 \\
1880 \\
1881 \\
1882 \\
1883 \\
1884 \\
1885 \\
1886 \\
1887 \\
1888 \\
1889 \\
1890 \\
1891 \\
1892 \\
1893 \\
1894 \\
1895 \\
1896\end{array}$ & $\begin{array}{l}17.1 \\
16.3 \\
16.1 \\
16.8 \\
17.2 \\
17.5 \\
17.5 \\
116.5 \\
16.1 \\
15.9 \\
16.1 \\
16.7 \\
17.4 \\
17.6 \\
17.0 \\
116.7 \\
16.5 \\
15.7 \\
15.2 \\
14.4 \\
14.9 \\
15.1 \\
15.5 \\
155.5 \\
15.1 \\
14.5 \\
14.2 \\
14.4 \\
14.4 \\
15.0 \\
15.5 \\
15.6 \\
15.4 \\
14.7 \\
15.1 \\
15.0 \\
15.8\end{array}$ & $\begin{array}{ccc}6 & s . & d . \\
13 & 0 & 8 \\
13 & 0 & 3 \\
13 & 8 & 0 \\
15 & 2 & 7 \\
16 & 8 & 7 \\
16 & 7 & 5 \\
17 & 14 & 5 \\
16 & 9 & 6 \\
17 & 0 & 6 \\
17 & 3 & 9 \\
17 & 10 & 3 \\
19 & 9 & 6 \\
21 & 0 & 0 \\
21 & 4 & 2 \\
20 & 11 & 0 \\
19 & 19 & 4 \\
19 & 0 & 10 \\
19 & 5 & 5 \\
18 & 2 & 1 \\
17 & 16 & 10 \\
20 & 3 & 3 \\
19 & 17 & 5 \\
20 & 8 & 10 \\
20 & 13 & 2 \\
19 & 4 & 1 \\
17 & 16 & 9 \\
17 & 0 & 10 \\
18 & 11 & 7 \\
18 & 12 & 1 \\
19 & 19 & 9 \\
19 & 19 & 7 \\
19 & 14 & 0 \\
18 & 15 & 6 \\
17 & 14 & 9 \\
17 & 11 & 9 \\
17 & 19 & 3 \\
18 & 14 & 1\end{array}$ & $\begin{array}{lr}s . & d . \\
53 & 3 \\
55 & 4 \\
55 & 5 \\
44 & 9 \\
40 & 2 \\
41 & 10 \\
49 & 11 \\
64 & 5 \\
63 & 5 \\
63 & 9 \\
48 & 2 \\
46 & 10 \\
56 & 8 \\
57 & 0 \\
58 & 8 \\
55 & 8 \\
45 & 2 \\
46 & 2 \\
56 & 9 \\
46 & 5 \\
43 & 10 \\
44 & 4 \\
45 & 4 \\
45 & 1 \\
41 & 7 \\
35 & 8 \\
32 & 10 \\
31 & 0 \\
32 & 6 \\
31 & 10 \\
29 & 9 \\
31 & 11 \\
37 & 0 \\
30 & 3 \\
26 & 4 \\
22 & 10 \\
23 & 1 \\
26 & 2\end{array}$ \\
\hline
\end{tabular}

(b)

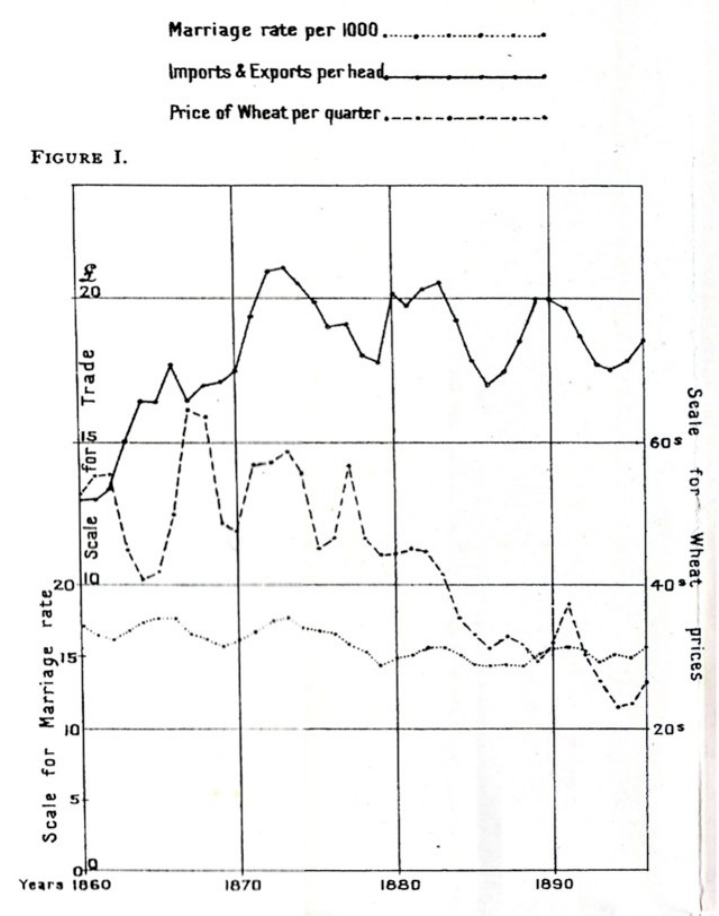

(c)

MARRIAGE RATE. AND IMPORTS AND EXPORTS PER HEAD.

Averages I $869-94$ on same line.

FIGURE III. Average fluctuations, 1867-95, equal.

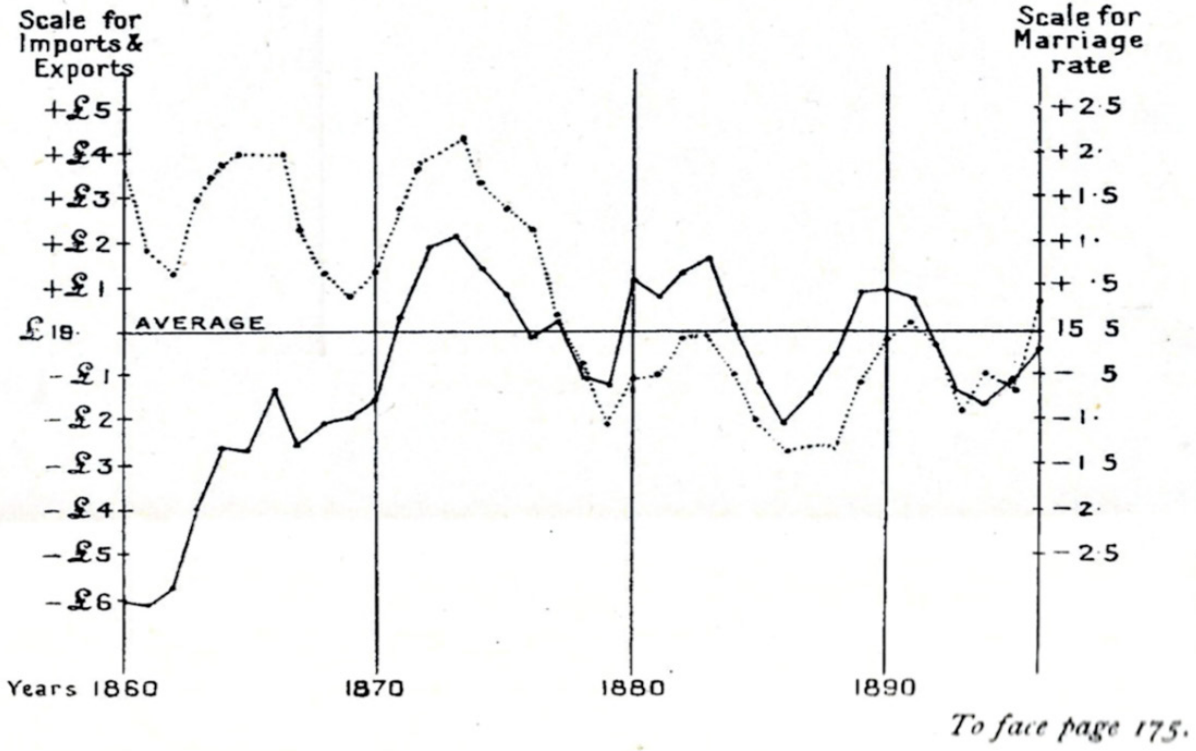

Source: Arthur L. Bowley. 1907. Elements of Statistics. Table p.174; Figures I and III p.175 London: PS King \& Son. 
Graphs emerged as a form of diagram particularly helpful for depicting data of phenomena that can be ordered over time, or space, by some other ordered property. In the fields of the examples used here, such diagrams often relied on the availability of data collected by the state (thus the important root of the term 'statistics'), such as demographic data, financial data, trade data etc., all data that were thought to be significant for the state, and which, during the nineteenth century, became public information rather than secret (see Nikolow 2001). While the contrast in these two figures epitomise differences between tables and graphs and so the nature of diagrammatic representation more generally, there were - as always - significant precursors as shown in Figure 3 ( $\underline{\mathbf{a} \text { and } \mathbf{b}) .}{ }^{7}$ They are well worth mentioning here because they point to something more general about the use of $2 \mathrm{D}$ space: and to what is, and to what is not, involved in inducing visibility by creating and using diagrams.

Joseph Priestley, notable chemist and man of letters of the mid-late eighteenth century is often credited with inventing 'the graph' in his immensely ambitious 2-D display, along a horizontal historical time line (or axis), of the names of notable philosophers, statesman, religious men, mathematicians etc. While such a graphic of history (only a small section of which is shown in Figure 3a) reveals which individuals overlapped in time, there is no meaningful order on the vertical axis, merely categories of fame which lie stacked on top of each other. This may have served as a revealing representation in showing who lined up with whom at some historical time period, but its reasoning and inferential possibilities are limited because there is no vertically expressed order or scaling that would relate the categories. In other words, it does not make full use of the second dimension of the representational space.

\footnotetext{
7 The most famous graphic of this fruitful late nineteenth-century period is Charles Minard's 1869 diagram of Napoleon's ill-fated Moscow campaign. This turns the known facts of the campaign into a visual representation, of which, more later.
} 
Figure 3 - Organising Visually, Using 2D Space

a) Small fragment of Priestley's massive biography chart showing: two vertical sections of 'statesmen' and 'men of learning' and time segments horizontally from BC650 to AD50.

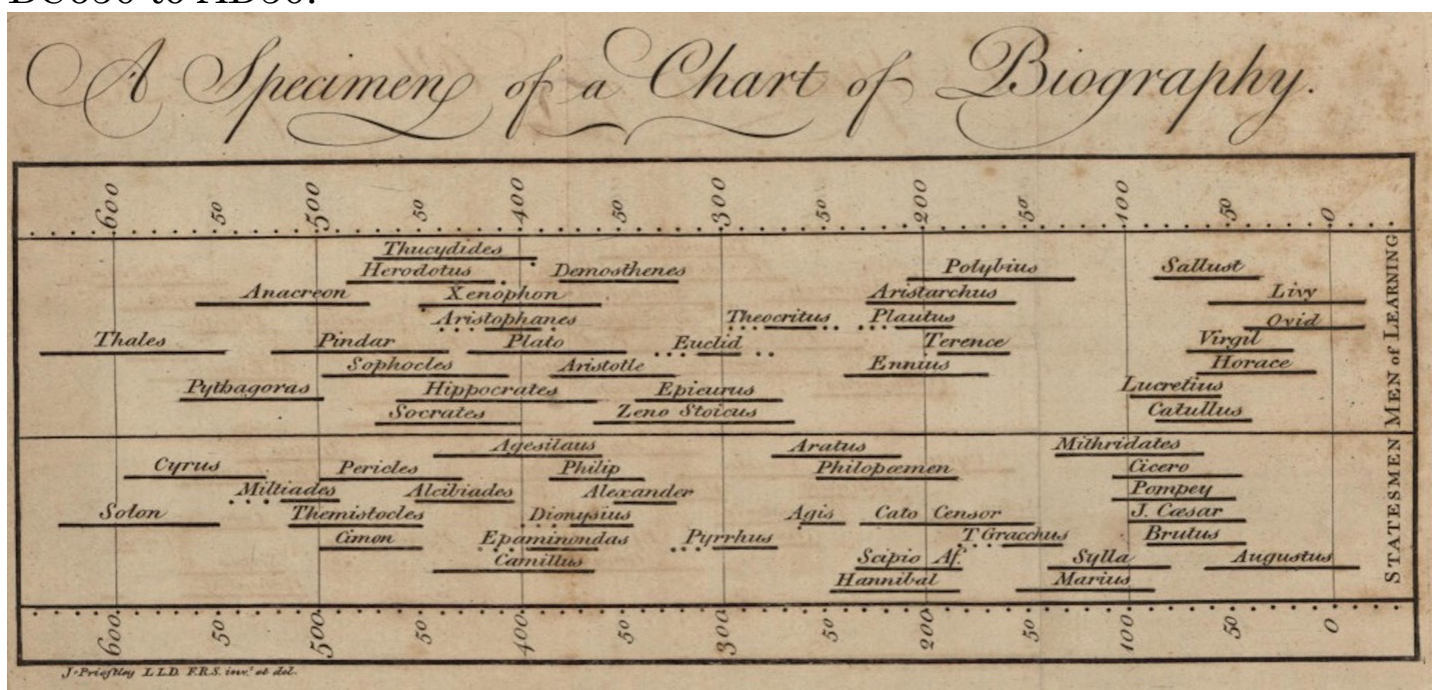

Source: Joseph Priestley. 1765. A Chart of Biography. London: Johnson

b) One of Playfair's many graphs of economic relations: plotting the trade between England and Denmark plus Norway vertically and the time period 1700 to 1780 horizontally to show how the 'balance' switched to be favourable to either side.

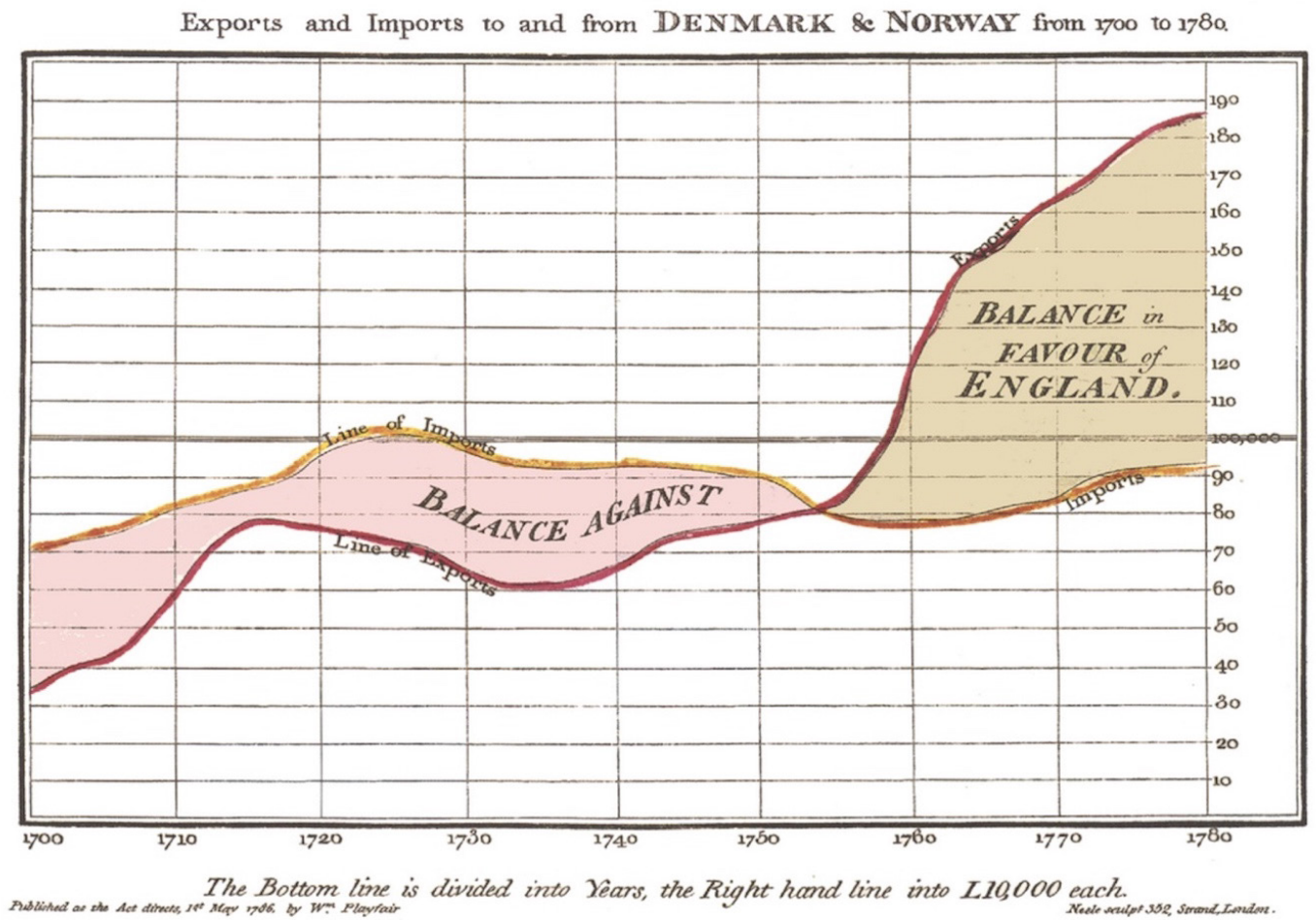

Source: William Playfair. 1786. The Commercial and Political Atlas. 3rd ed. edition 1801 
In contrast to Priestley's display, we have the set of diagrams created by William Playfair (engineer, political economist and possible secret agent), credited as the inventor of statistical graphs in the early nineteenth century for developing genuine 2-D statistical graphs in political economy using data on trade, prices, and so forth. With both axes informative, and with time on the horizontal axis, we see how diagrammatic representations use both dimensions of the 2D space in ways that both reveal states of affairs and offer possibilities of reasoned inference. Figure 3b is one good example from Playfair's work, showing two simple lines which not only reveal visually the path of two different elements (which might indeed have been gained from a table) but also reveal - without any tedious comparison (let alone addition or subtraction on the part of a tablereader) - the "balance in trade "between the UK and two Nordic countries. In this period of the late eighteenth and early nineteenth centuries, such a balance of trade was a critical question, both in terms of evidence and for theorizing by the political economists of the day, as well as extremely salient in the public domain.

Other kinds of examples offer the same revealing and inferential resources. One such is the set of diagrams produced by August Crome in the early nineteenth century to depict the relative strength of states in ways which replaced both words and numbers. These diagrams (examples are shown and discussed by Nikolow, 2001) have features of both tables and maps, but are neither: they use relatively-sized rectangular spaces and circles in the $2 \mathrm{D}$ space to provide a visual comparison of the relative resources of the different European states in order to reveal their relative political and economic power. Other graphs depend neither on time nor space in their use of graphs, but on other features of phenomena that can be ordered along two dimensions. Woody (2014) for example discusses graphic representations in chemistry of the periodic law, ordering atomic weight versus atomic volume on the two axes. 


\subsection{Indicating and Revealing}

I want to pick up two points from these first examples of inducing visibility. First, the line between indicating and revealing in creating diagrams is thin indeed. They cannot really be separated, for the scientist in choosing how to represent things in a diagram both indicates and reveals hidden or non-obvious information in the relative position, variations, and sizes of the lines in a graph or shapes in a diagram. Second, these indicating and revealing roles depend not only on the use of both dimensions of the $2 \mathrm{D}$ space in depicting those things, but also on the metrics used in the representations; care with both are needed to indicate patterns, relatives and relationships. The spatial aspect is naturally important - both dimensions are important otherwise there would be no payoff from working with the resources of $2 \mathrm{D}$ and in employing visual reasoning and judgement. 8 The metric aspect itself has two elements: one is the choice of metrics in scaling; and the second is the topological aspect. Diagrams of empirical materials depend on both aspects, and thereby, of course, on the skills, knowledge and choices of the scientists in developing such metrics for their subject matter in order to make their diagrams a revealing technology and a useful or usable tool. Diagrams don't draw themselves (even with big data, machine learning, and automated computer programmes: someone has written the initial code and filled in the parameters). And nor do diagrams use themselves. Rather, diagrams are made and shared within a community of scientific users, usually with highly specialised diagrams particular to usage in that community. Despite this, there are generic points to be made.

Marcel Boumans (2016) recently argued for the importance of visual judgements, or rather the eye as an expert, in the ways that scientists frame statistical numbers and fashion them into lines in diagrams. Almost never in the social

\footnotetext{
8 From this point of view, the schematic diagrams which join up labelled boxes with arrows found in parts of biology and the social sciences to depict causal relations, mechanisms, and pathways, do not make full use of the dimensionality potentialities of the $2 \mathrm{D}$ space. Because they do not make full use of any metrics nor subject structure in form-content, they 'float' on the paper, limiting reasoning possibilities, as will emerge later in this paper.
} 
science fields that concern Boumans are raw data presented directly in diagrams. He gives a detailed account of the processes of treatment and manipulation that result in the time-graphs that were constructed by their innovator, Warren Persons, from business-cycle data and regularly used by economists and market commentators in the 1920s (see Figure $4^{9}$ ). The lines are the result of elaborate processes of composing together separate time-series data on different financial and economic phenomena into composite indicators of the business cycle. That composition process depends on rules that are mechanical and ingenious as well as on visual judgements. The individual numbers - the 'items' that make up the statistical data series - are already firmly ordered in time. They cannot be taken out of time order, but they may have particular time-based variations (eg seasonal variations) removed from them. And each series can be related to others in the same space - but not necessarily exactly for the same calendar time as measured along the horizontal axis - for some series 'lead' the cycle and others 'lag' behind. The lines joining up the treated numbers were represented in accordance with the (by then) established conventions of graphic work on this topic, with time on the horizontal axis and scaled vertically to be above or below a 'trend' line of the economy over time. No longer raw numbers, interwar economists took these lines to represent the business cycle: for, as the OED definition suggests, these several associated lines of marks "represent symbolically the course of results of any [...] process".

\footnotetext{
9 This particular example is from one of Persons' collaborators, W.L. Crum.
} 
Figure 4 Revealing Data Patterns: Composing the mess of individual economic indicator series into a graph to uncover business cycles in the first 'business barometer'.

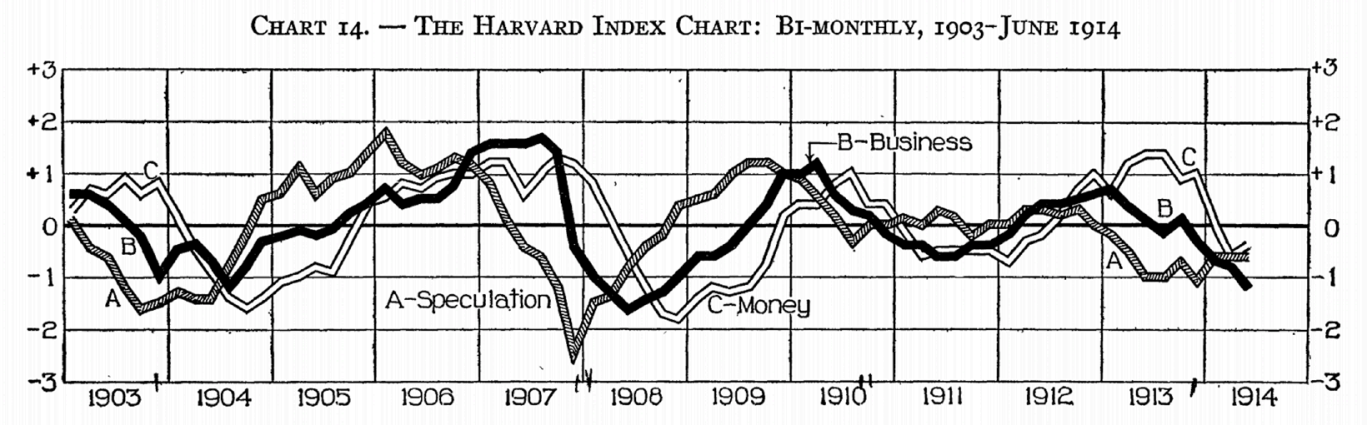

Source: Crum, W. 1925. The Interpretation of the Index of General Business Conditions. Chart 14, p222. The Review of Economics and Statistics, 7, 217-235.

Whereas Boumans is interested in how visual judgements are used to create those lines in a reliable way, that is, in the processes of turning raw observations into organised and meaningful lines on the graph; I am more interested here in the revealing aspects of the resulting diagrams, and so the sense that those scientists gained of the phenomena of interest they were aiming to represent. That is, the eye used not as a measuring judge, but as an instrument of perception and inference: of sense-making, and pattern recognition. The business cycle was an ill-defined phenomenon in this period, and visual representations of this type were the result of following community views both about what it did not involve (not seasonal variation, not long-term trends), and what it did involve: a number of economic aspects that interacted or interrelated, but were not clearly described by any agreed causal mechanism or neat theory. The lines of marks in the diagrams revealed by Persons' complex treatments (such as in Figure 4), suggest both the regularity and irregularity of the processes of economic activity, and their heterogeneous elements. Their spatial form - in sets of curves moving together and apart over time, with different non regular and complex variations - offers the most succinct form of how economists described and understood the empirics of business cycle phenomenon in the early twentieth century. 
These lines in combination formed what was called a 'business barometer', an inference tool for the community to predict the timing of future changes in the economy. Use of this diagram as such a diagnostic tool was based on the confidence it provided in mapping or tracking the past history of the economy according to those lines. We can see clearly here the difficulty of treating the diagram as a revealing diagram separately from its inferential possibilities for it fulfils both functions at once. As Boumans suggests, the whole process of creating and using the barometer is a work of "graph-based inductive reasoning".

Boumans also points to alternative (and sometimes complementary) forms of manipulation and assembly for such data lines that rely on topological manipulation, ${ }^{10}$ that is, on stretching or compressing the lines so as to keep the same topological relations (as in caricatures) rather than by composing or decomposing the data series according to its time-component elements. For both approaches, the purpose is to reveal, and make inferential use of its components.

We see the topological work in Figure 2c, an example which comes from Arthur Bowley's work of the very early twentieth century. Bowley (one of the preeminent social statisticians of the period, renowned not just for the introduction of random sampling, but perhaps the first statistical textbook for social scientists) figured out means to transform two data series to induce visibility of their relationship by creating a diagram in which inference might be drawn between the relative variations (not absolute values) in these two factors. This involved going further than charting the table of numbers for the marriage rate and trade (from Figure 2a to Figure 2b). In Figure 2c, he transformed the data, and reconstructed the chart to depict the two series on a base line representing the average value in both series, and adjusted the scales on the two sides to show the closest match for their variations (particularly the positive co-

10 Topological manipulation, and its cognitive aspects, are explored for cases in mathematics in Giardino (2018). 
movements in the later part of the graph). Following this topological treatment, the new diagram reveals co-variations that were hardly visible in Figure $\mathbf{2 b}$. While Bowley's method can be interpreted as a graphic method of correlation (based on the technical manipulations and representation made), the outcome is not a single number but rather a spatially depicted relationship on the diagram which shows far more information about that relationship than the equivalent single statistical correlation coefficient would do (see Morgan, 1997). Even though that correlation coefficient makes use of all the same data and so contains all the same amount of 'information' as the diagram, the latter offers a more revealing technology by making full and effective use of the dimensions of the $2 \mathrm{D}$ space.

\section{Spaces and Dimensions of Reasoning}

The possibilities of reasoning with and from these kinds of diagrams raises the question that Larkin and Simon (1987) address in asking when reasoning with a diagram is better than reasoning with $10 \mathrm{k}$ words. They argued that a diagrammatic form of representation is better (more "efficient" in a cognitive science formulation) for solving problems than a sentential representation when - I infer from their overall treatment - a) the material at issue can be spatially depicted and involves items that relate easily in a diagram but are difficult to relate easily and efficiently in sentential languages; and b) when the reasoning involved with the relations does not work easily in sentential form. It is significant for this paper to note that for them "a representation consists of both data structures and programs operating on them to make new inferences" (p65), that is, it is not just the diagram's form, but the operations that can be used on it, that matter for answering questions with a diagram. Like Boumans they privilege the eye - but for them, the relevant property of the eye lies in enabling perceptual judgement about relationships rather than in judging smoothness and shapes of phenomena from numbers (the focus of Boumans' discussion). Their point is that "efficiency" in "search, recognition and inference" depends on 
a combination of the eye and the diagram, to obtain "perceptual results" at almost "zero cost" (p92). Their argument is buttressed by a thorough analysis using their two main examples of pulley systems and geometric proofs, which involved translating those diagrammatic depictions and associated reasoning tasks into equivalent sentential modes of representation and problem-solving.

Larkin and Simon distinguish, with their examples, between diagrams that "describe systems in real ... or ideal" spaces, and graphic diagrams which they label "artificial diagrams" ie ones which "do not describe any actual spatial relationship" (Larkin and Simon, p 93). I suggest it is better to label the latter, not "artificial diagrams", but 'diagrams in artificial space'. Let me explain: from Larkin and Simon's viewpoint, a map is a diagram of a real spatial system, a pulley can inhabit real space - so both can be described in a diagram in a similarly spatial world; that is, these diagrams map spatial dimensions of the object onto spatial dimensions in the diagram. A geometric diagram inhabits an ideal spatial world, the abstract ideal world of mathematics. In contrast, many diagrams drawn by scientists do not depict materials that exist in any real spatial system, but rather these scientists create artificial spaces, where the shapes and relations of their subject matters - that are not literally spatial - can be represented spatially into a $2 \mathrm{D}$ format. Thus the messy graphs of statistics of the business cycle, or the circles and boxes of comparative power of European states, are each drawn into an artificial space constructed on paper to represent something in the world which is not inherently a spatial system. The space of the human and social scientific diagrams of Figures 2 to 4 involve artificial spaces in which the numbers coming from a complex human and social system are used to depict lines or areas. The axes provide the grounding for the relative positions of the lines and shapes; and by making such decisions about how to depict their materials, the scientist creates, describes and limits an artificial space which enables inferential or deductive reasoning about the objects depicted within that artificial space. I stress that there is no one kind of artificial space. Each kind of artificial space is constructed by a scientist or 
their community when they choose to depict their subject matter in diagrammatic form. ${ }^{11}$

The critical point I take from Larkin and Simon is their conclusion that such diagrams in artificial spaces are as equally open to 'perceptual' enquiry as those in real and ideal spaces. Diagrams in artificial spaces can prompt recognition, and perceptual judgements, that enable the scientist to answer questions about their materials that it would be almost impossible to answer, and more important - perhaps not even arise - in other forms of representation. And, when diagrams can make use of $2 \mathrm{D}$ space to depict relations, it may also be that those diagrams can be used to solve problems framed in that space more effectively than in using a large number of words (Larkin and Simon's claim), or more than a long list of numbers in a table.

But such diagrammatic enquiry is only possible, and hence potentially productive, when the visual form in which the scientific subject matters are represented gives them, and can make use of, spatial properties. For example, Priestley's diagram (Figure 3a) does not activate such perceptions or productive inferences because - as I pointed out - it does not make full use of the spatial properties of the vertical dimension. The important contrast seen in the diagrams of Figure $\underline{\mathbf{2 b} / \mathbf{c}}, \underline{\mathbf{3 b}}$ and $\underline{4}$ is that they make use of both dimensions of the space: having productive vertical axes means the diagrams can reveal the variations in each line, the relative movements of the different lines, and the relative lack of smooth behaviour. None of these can easily be captured in words or sufficient statistical measures, showing how a diagram in artificial space can be a better format of representation for interrogating those traces of evidence. As is evident from the contrast between $\underline{\mathbf{3 a}}$ and $\underline{\mathbf{3} \mathbf{b}}$, the artificial space of a diagram needs to be structured in some way to enable the diagram to

11 For example, Perini (2013) examines the kinds of diagrams and schema that biologists habitually use and classifies them according to their content and form; Sheredos et al (2013) offer another analysis of biological diagrams according to their functions. Some of these diagrams use artificial space, and others real, though this characteristic is not part of their analysis. 
be grounded for use in that space. And as is evident from the comparison $\underline{\mathbf{2 b}}$ and $\underline{\mathbf{2 c}}$, there are various ways to do that.

As we have already seen, the most obvious way in which 2D space is structured is by some form of axes, whether scaled or merely ordinal. At first sight, this does not seem to be very flexible and, neither do the modes of reading that space, for Krämer points out that the basic ways in 2D space can be read: up and down, right and left, and centre and periphery are not "interchangeable" (Kramer, 2016, p210). But even so, there is considerable flexibility in what can be depicted - both in terms of the myriad number of things that can be put into the diagram, and in the different content forms of depiction.

To start with, the two dimensions of 2D space do not constrain the scientist to depict only two aspects of their materials. Minard's famous 1869 graph of Napoleon's Russian campaign, much lauded in Edward Tufte (1983) is a mixedspace diagram. It is partly one of real space (because of its qualities as a map in which distances provide the basic metrics for the graph) and partly uses artificial space in depicting the size of the army (as depicted by the width of lines on the graph) and temperature (depicted at key points in the campaign in a time-series graph below the distance graph/map). ${ }^{12}$ All this information could have been given, and surely has been, in verbal formats, but the succinct form of putting all these separate bits of evidence together has tremendous revealing power. The main point is not that you could not make the arguments or reveal the components in another form: historians have undeniably done so in sentential form in this case - but that, applying Larkin and Simon's main point here: the diagrammatic form is much more efficient for revealing the problems that beset the campaign, and for making inferences about the factors that lead to

\footnotetext{
12 We might be tempted to suppose that temperature is depicted in a real space diagram, but we are really referring to the indicator on the measuring instrument for temperature, ie to conventional numbers on the thermometer. Just having numbers as a good measure of empirically accessible things (size of army, temperature) does not mean that the phenomena to which they refer are spatial phenomena and so are diagrammed in real 2D space.
} 
Napoleon's defeat. Tufte argued that "it may well be the best statistical graphic ever drawn” ((1983, p40).

Minard's diagram helps us to recognise that the 2-dimensionality of a representational space (constrained by the surface on which a diagram is drawn) is not necessarily a constraint that means a scientist can only recognise or reason about the relation or parallels between two different things, either in the empirical domains (discussed above) or in the abstract or theoretical domains (to be discussed later). We have already seen in the statistical graphical diagram of Figure 4 using artificial space, that a flat $2 \mathrm{D}$ artificial space can be used to depict many items when all are ordered in time (and even at different time delays), and they can show associated series and possible relationships between many more than two factors, just as the pulley system depicted in real space can have many elements. Time and mechanical connections offer two kinds of orderings or relations found in many different subject matters using real or artificial space that can be depicted onto a $2 \mathrm{D}$ surface.

In practice, the spatially structured possibilities of $2 \mathrm{D}$ space are actually very flexible, not just for the depiction of many things, but for depicting many different characteristics of something, and for depicting many different kinds of relations or properties of those things. In one, possibly extreme, example: architects' diagrams are concerned with depicting the physical aspects of things in three dimensions onto $2 \mathrm{D}$ space, and do so in relation to human scales, so architects' design diagrams can be considered mainly diagrams of real space. But they can also show many additional elements: using shape, size, position, and direction to depict not only walls, rooms, etc, but also indicate human experiences of sound, light, heat, wind and rain patterns, as well as human concerns such as privacy (see Do and Gross, 2001). An equally fruitful example comes with diagrams of crystals. Elkins (1999, Chapter 2) dissects the many different ways in which crystal diagrams use the full possibilities of $2 \mathrm{D}$ real space to reveal different $3 \mathrm{D}$ properties by using different conventions of 
representation. His historical survey runs from drawings of actual crystals in the early eighteenth century, through depictions of how crystals fit together (including diagrams of crystals' 'habits'), and in parallel and stereographic projections. Some of these representations are drawings, some are diagrams of idealized forms, and each form of diagram offers different insights into the properties of crystals.

These are just two specialist field examples, but the possibilities are considerable, and now extended with computer graphic methods. Elkins, in his (Chapter 13) discussion of schemata (the category that is closest to diagrams here) refers to the use of axes, scales, lines, nets, grids, rulers and lattices, on which can be drawn circles, trees, columns, bars, and nets as well as lines and points. The social sciences produce decision trees, network diagrams, flow diagrams, causal chains, etc, all of which are fitted into, and grounded in, 2D artificial spaces. Figure 5 depicts two examples of such diagrams to indicate a little of the vast variety. Figure 5a depicts a group structure of a 'street corner' gang from William Foote Whyte's analysis of a North Boston slum in the 1930s. Formal axes are absent, but the social hierarchy is completely obvious in this 2D artificial space. Figure 5b provides a diagram from a parallel study of social groups in a Southern black/white town in the same period. It maps individuals in the black community into their social groups. The grouping uses age (horizontally, like time) and class ranging from "LL" (lower lower class) to "U" upper class, (vertically expressed by convention) to depict the membership characteristics of different special interest groups or 'cliques'. 
Figure 5 Group and Caste Maps: Using the 2D to depict social relationships

a)Whyte's map of the relationships of individuals in a 'street corner' gang in Boston in the late 1930s.
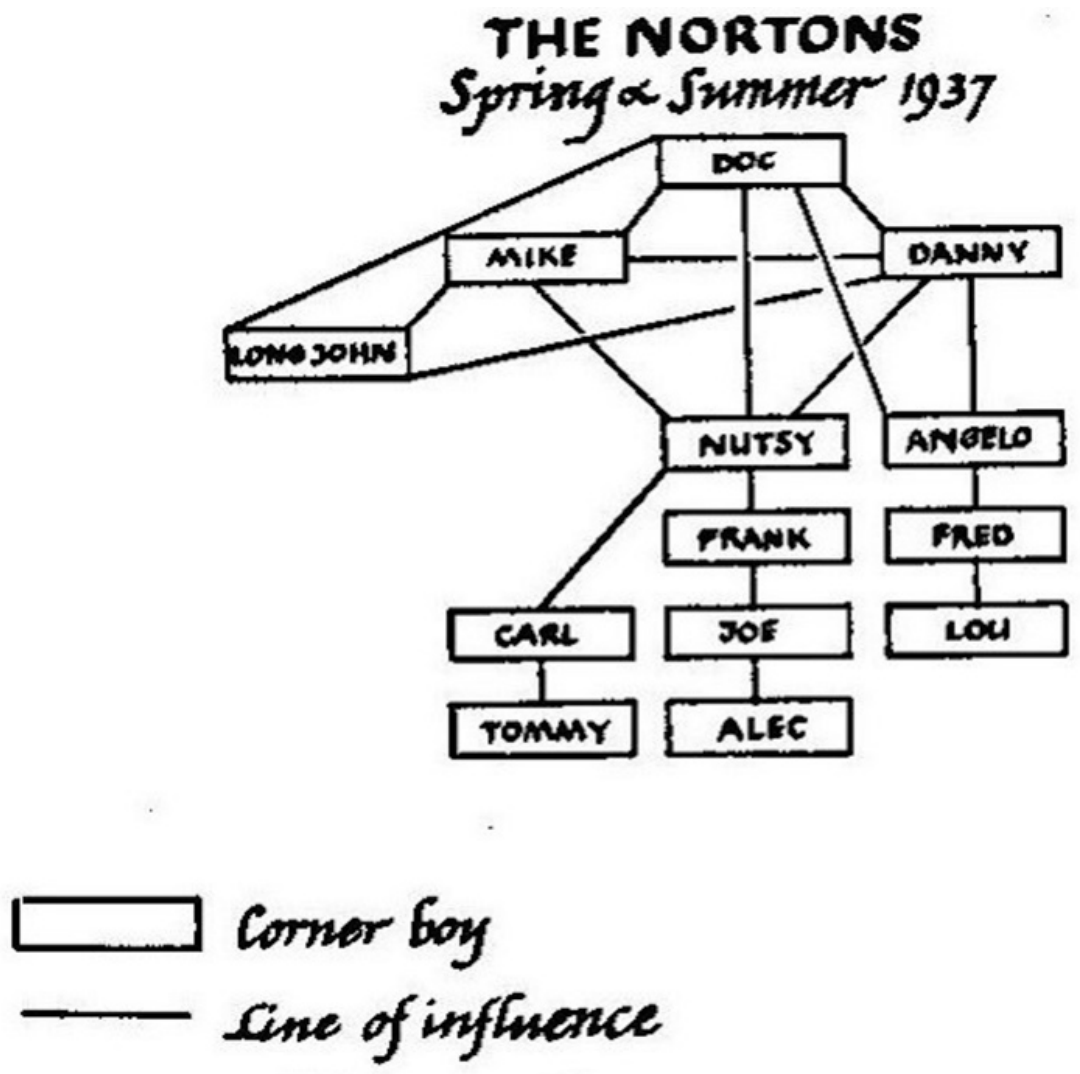

\section{Positions of Goxes indicate relative status}

Source: William Foote Whyte. 1943. Street Corner Society: The Social Structure of an Italian Slum. From Chapter 1, p13. Chicago: University of Chicago Press. 
b) Davis, Gardner and Gardner's map of the social stratification amongst the African American community in Mississippi in the early 1930s, arrayed by age horizontally and by class (Upper down to Lower Lower class) vertically.

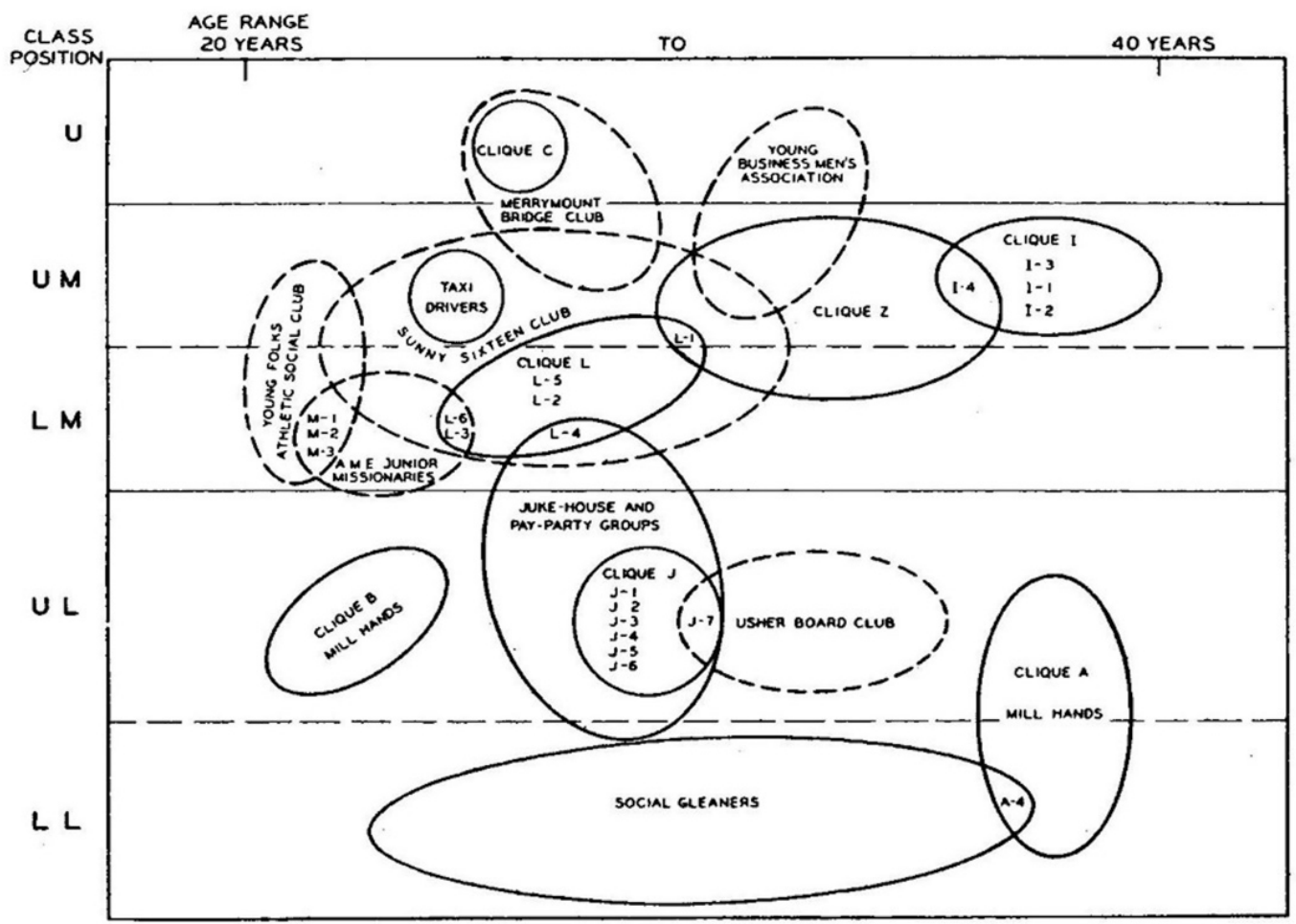

Fig. 13.- Social stratification of a group of colored cliques and associations, ages 20-40. Where overlapping occurs, at least one person is in both groups, and is of the social status and age-range indicated by the general area of overlapping. (Key:,-- , associations; $-\longrightarrow$, cliques.)

Source: Allison Davis, Burleigh B. Gardner and Mary R. Gardner (1941) Deep South: A Social Anthropology of Caste and Class. Figure 13. Chicago: University of Chicago Press.

At this point I return to my main argument to make the next step. Diagrams in artificial space do not depict spatial relations between objects in the world, such diagrams use artificial space to depict and reveal other kinds of relations. So long as these presented relations in the diagrams are constructed to use the properties of 2-D space, they can potentially fulfil Larkin and Simon's argument that they provide for efficient problem solving. But such problem solving using the resources of such diagrams in artificial space does not necessarily lead to inference beyond the diagram to the real objects and relations depicted in those diagrams. 
Making inferences with diagrams depends on subject matter knowledge of course (it always does). Much of the time, scientists make inference within the diagram about the relations between the objects depicted in the diagram: that is about what is being revealed, in patterns, in co-movements, etc. and about what can be argued for given the reasoning using the diagram. More problematic is any inference made from the results of either empirical or theoretical reasoning made in using the diagram back to the world, that is, to the system, objects, and relations depicted in the diagram. ${ }^{13}$ This is a big topic, but it seems reasonable to suggest that while some inferences from diagrams using real space might be feasible, it is likely more problematic for diagrams using artificial space. Downes (2012) argues (for diagrams generally) that inference from diagrams is more difficult than from images such as photographs of various kinds, because the latter offer 'direct representations' which depict (and in some way look like) the object that they represent. Diagrams don't represent in this 'direct' way, rather they are "inferentially distant from their objects" (Downes quoting Roskies, 2012, p 123). On the other hand, inferences from diagrams might be more 'legible' than those from images such as photographs, because lots of (arguably unimportant) details are omitted in the diagram. This certainly seems to be relevant to inference within the diagram. However, this benefit does not extend to inference back to the world in any immediate sense. Diagrams can clarify the hypotheses about what happens in the world either empirically or theoretically but these hypotheses from diagrammatic reasoning may have to be carefully examined with other methods of science in order to make valid back-tothe-world inference, particularly when the space of the diagram is artificial. ${ }^{14}$

\footnotetext{
13 Of course, such 'back inference' is in any case problematic for all sorts of scientific research not just that using diagrams - very obviously with model work and case work, but even for experimental work, where the strict controls in the lab may make inference beyond the lab difficult. There is a large literature, part surveyed as the problem of 'resituating knowledge' in Morgan (2014a).

14 Diagrams in mathematics might be different, for here inference within the diagram does not need to be inferred back to the world, but rather remains argument and proof within the diagram: now understood as deductive rather than inductive proof. Of course, diagrammatic work in mathematics may support broader theoretical work at a more generic level, as perhaps in knot diagrams in which case inference or deduction can be within and beyond the diagram to speak to more general mathematical claims (see De Toffoli and Giardino, 2014). But those
} 


\section{Visualizing and Visual Deduction}

While many sciences have relied on the inductive use of diagrams using empirical resources, scientists have also developed their own forms of diagrams to encourage visual deduction. These practices of visualizing involve the construction of diagrams to represent the imagined relations or hypothesized objects and phenomena of their sciences at a theoretical level. They are widespread in the sciences, many using artificial not ideal spaces, and usually highly specialised to a community of scientists. Usage of such diagrams involves not so much recognition in empirical materials of shapes, movements, changes and so forth over time but rather envisioning in diagrammatic form the properties, behaviour, causes and associations that are involved in abstract, conceptual or theoretical materials in order to reason about those materials. In the context of a study of the history of graphs, Judy Klein has labelled the kind of arguments made with these theory-concept diagrams as reasoning about "logical time law curves" (versus the analysis of "historical time fact curves" of the type discussed earlier in this paper). ${ }^{15}$ She refers here to the reasoning about the possible things that can happen in these scientifically imagined worlds, where these 'logical' changes are determined by the scientists' theories about the phenomena as represented in the diagram. Reasoning with these theoretical-based diagrams enables scientists to explore the content of their theories, suggest new hypotheses or close off others, and so forth.

The classic example of these theory-based curves in economics are the supply and demand diagrams that Alfred Marshall drew in the 1890s shown in Figure

6. The creation of such diagrams first of all involves imagination about the way

direct mathematical deductions are surely different than using knot diagrams to model idealized DNA diagrams, in which case inference from the ideal space mathematical diagram to the artificial space source field diagram of DNA is a 'back inference' problem that requires other support (see Priest et al, 2018).

${ }^{15}$ In fact, Klein (1995) offers a four way analysis of diagrams, drawing on many historical examples in science going back to Nicholas Oresme, but the main force of her argument is based on eighteenth and early nineteenth-century examples including the seminal forms developed and used by Johann Lambert, James Watt and William Playfair. 
the world is, and how it works, to depict the range of possibilities in the different shapes of the curves (see Morgan 2012, and 2014). Their subsequent usage involves a different cognitive practice from either perception or making eyeball judgements, but one that appeals to visualizing skills to make deductions visually from working with the diagrams.

Figure 6 - Marshall's Visual Deduction with Diagrams in Supply and Demand Theorizing
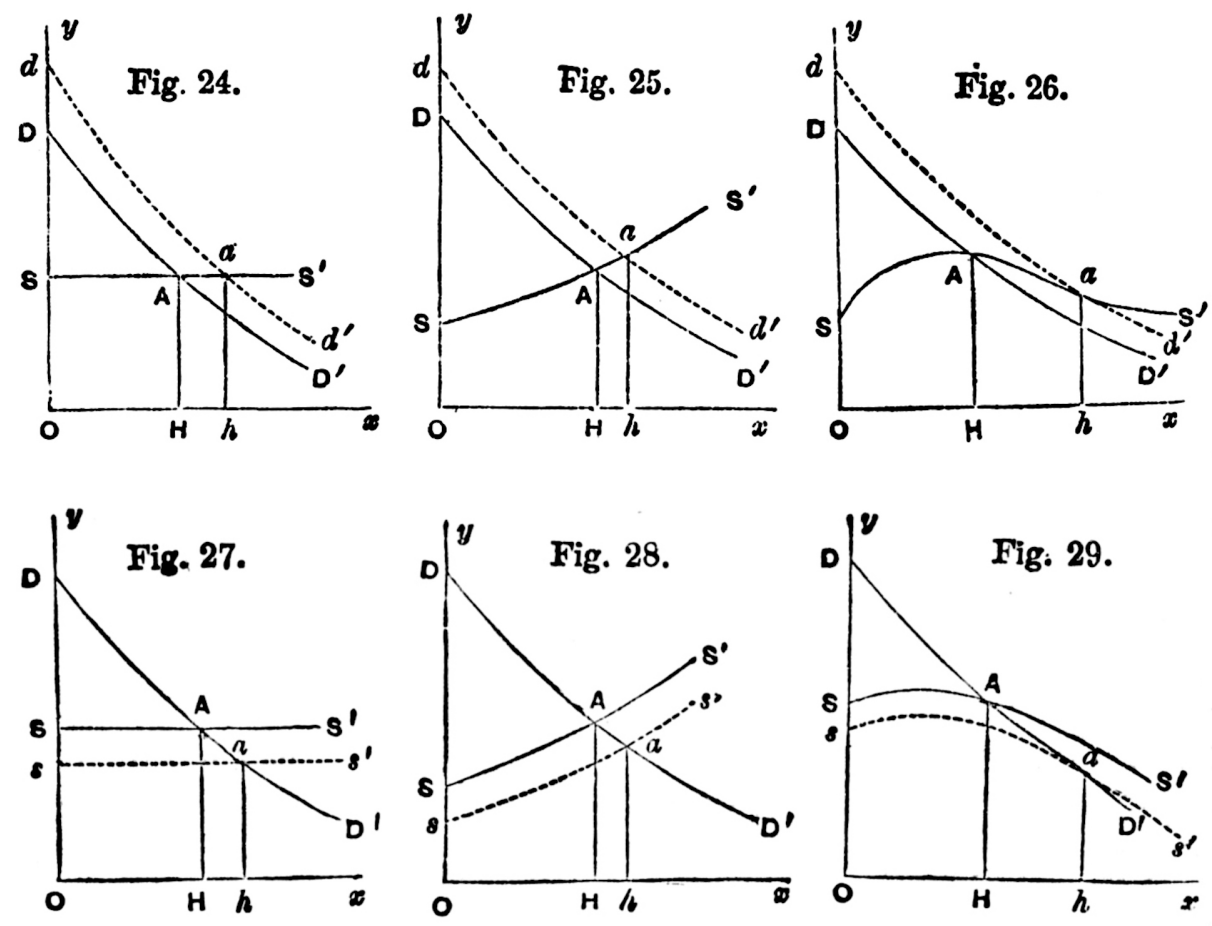

Source: Alfred Marshall. 1890. Principles of Economics. London: Macmillan. Book V, Chapter XIII, Figures 24-6, Note 1, p. 464; Figures 27-9, Note 1, p. 466. Reproduced with acknowledgement to Marshall Library of Economics.

Interestingly, Larkin and Simon use these very same Marshall diagrams as examples of their "artificial diagrams", although as I suggested above, it makes more sense to refer to these as 'diagrams in artificial space'. Using imagination to give form to such theoretical ideas in $2 \mathrm{D}$ artificial space requires adopting some metric, or device, in which to pin down the diagrammatic structures within that artificial space. Real space diagrams such as geographical maps are 
pinned down by the 2 and 3 dimensions of the real space depicted in the representation: the north/south/east/west dimensions, and the topographical height lines. Geological maps use 2D real space to chart layers of different strata beneath the surface that lie over each other. In contrast, and at first sight, these late nineteenth-century diagrams from Marshall appear to be unconstrained by any feature that pins the diagrammed objects into the artificial space they inhabit; there are no obvious metrics or topology compared to those found in the earlier examples of statistical graphs. But just because a space is artificial does not mean that its space is arbitrarily defined; rather the space of such a diagram is defined or pinned down by the concepts, definitions, and theories of the subject matter of the science.

In terms of depiction, the curves in Marshall's diagrams, represents how economists hypothesize that consumers and producers imagine they might behave, with quantities on the horizontal axis and prices on the vertical (see Morgan 2014). The market-level SS supply curves depict how economists hypothesize producers (as a group) might respond in changing their supply as prices rise and the market-level DD demand curves depict how consumers (as a group) might respond as prices change. The supply and demand curves depicted therefore occupy an artificial space defined by the relations of prices and quantities, both envisaged on an ordinal scale on the axes - the diagram enables the theorized behaviour of consumers and producers to be depicted together. These abstract, concept-based, diagrams developed out of earlier descriptions of the 'laws of supply and demand' which were verbally couched using arithmetical terms describing consumers and producers responding to higher or lower, rising or falling, prices.

Using such diagrams requires a degree of imagination along with a facility for deductive reasoning to explore the hypothesized relations using the diagrammatic resources. For economists, this exploratory-explanatory reasoning uses the theories of supply and demand behaviour to explore various 
possible reasons (or hypotheses) for changes in the curves, tracing through the steps of the argument to an outcome using the diagrams of Figure 6. (For example, these could include a change in income that changes the DD curve's position, or a change in technology that shifts the SS curve.) Marshall himself asked four questions with each version of the diagram: what would happen if the demand curve shifts up or down (ie changes the quantity demanded for all prices); what would happen if the supply curve shifts up; and what happens if there is a tax on the good (so as to increase the price)? I have described these processes of usage elsewhere as 'model experiments', experiments that involve deductive reasoning by manipulating the diagrammatic model. ${ }^{16}$ Some of these deductive visual experiments were done by Marshall physically drawing the shift in the curves in the 2D space of the diagram; others were done as mental spatial deductions, only possible because the answer had become obvious from the previous visual diagrammatic reasonings. Priest (2018), in writing about Darwin's invitation to readers to imagine different scales on his 'tree of lifediagram, refers to the such mental visual reasoning as "manipulative imagination", an apt label for a practice once a diagram has become well accepted and used in a community. ${ }^{17}$ Giardino (2018) uses that term in discussing experts' reasoning with knot diagrams in mathematics; and she also introduces the term "representational affordances" to provide a sense of the enabling possibilities of diagrams. Diagrams prompt the manipulative imagination, but at the same time they anchor and constrain the manipulations that are possible. The visual deductive reasonings with the diagrams of Figure $\underline{6}$ gave Marshall a testing ground for his theories in figuring out what kinds of

\footnotetext{
16 See Morgan, 2012, Chapter 7, and before that, Morgan, 2002 on model experiments. I would not want to call the exploratory work done in these kinds of experiments on diagrams representing theoretical claims as counterfactual since these are not 'fact-based' diagrams. There are fact-based experiments done on empirical diagrams in economics, some of which might count as counterfactual, but are more usually referred to as 'scenarios' or 'simulations'.

17 One might have used the term 'thought experiment' here, but 'manipulative imagination' works better because the diagram both constrains and anchors the reasoning, and so the manipulations that are possible.
} 
things might happen in an hypothesised world whose relationships and behaviours were pictured in the artificial space diagram and tracked in its usage.

The manipulative possibilities, both on the diagram using the diagram, and mentally in thinking with the diagram, are key to the claim of deductive reasoning. Such reasonings may also involve mathematical operations. Once again it is worth emphasising that this is not a particularly social science mode, but rather a generic mode of using diagrams within the sciences wherever the diagram affords the use of mathematics at certain points. For economists with their diagrams, it was a simple step to indicate optimum points by depicting tangencies to curves: thus bringing mathematical reasoning into the argument, where it was efficient to do so. Chao (2018) discusses how geographers (between the 1820s and 1930s) created and understood their location theories directly in terms of ideal geometric shapes: concentric rings, triangles, and hexagons; and then reasoned about the properties of location in terms of such ideal mathematical spaces. He points out how later economists reversed the process to argue from their mathematized theories into spatial interpretations in diagrammatic form. Wise (2017) discusses how visual simulations of the processes of chemical bonding rely on diagrams based on mathematical models to explore the multiple paths to such bonding using computer simulations. Priest, et. al. (2018) discuss how the DNA double helix diagram was first reasoned with by depicting its $3 \mathrm{D}$ qualities in a $2 \mathrm{D}$ space using linking struts and up and down arrows. As they tell it, knot diagrammatic methods of manipulation were subsequently applied to the DNA double helix diagram, but only following some discussion with the mathematicians as to whether the subject content of the DNA diagrams allowed for such mathematical treatment.

Diagrams - as other forms of representation - both 'constrain' and 'afford'. Reasoning with diagrams, both physically and mentally, offers a demonstration system for exploring theoretical possibilities about the phenomena, not an illustration system of what is known about the world. Such deductive inference 
is a process of using the diagram to learn about what the diagram can and cannot teach the scientist about the nature of the imagined world, not a visualization that could easily validate direct or indirect inferences to the real world that is being depicted. Provided that the diagrammatic materials are pinned down into $2 \mathrm{D}$ space and structured in some way to depict and so constrain their relations in ways that are consistent with the subject matter, then Larkin and Simon's claim about reasoning and problem solving with diverse kind of diagrams in artificial space work in much the same way as for the real and ideal forms of diagrams they analysed. What is perhaps less evident is that each space - ideal, real or artificial - potentially has its own language and grammar used by the scientist in working with their diagrams.

\section{Modes of Diagrammatic Reasoning}

Reasoning with diagrams - visual deductions - relies on both the content of the diagram and its rules of manipulation or operation, both of which are determined in large part by the subject matter and how these are imagined and visualised. The meanings and rules of behaviour of the subject matter supply the vocabulary and grammar of the diagrams. ${ }^{18}$ For example, the vocabulary of kinship diagrams shows the possible array of relationship connections, but analysis based on many anthropological studies of different cultures suggests that there is more than one system - or grammar - of kin relations that can be depicted in kinship diagrams: there are two types (and perhaps an extra half, see Read, 2013). The typical European kinship pattern depicts horizontal and vertical relations, is 'read' downwards (usually) by generation, and allows, for example,

\footnotetext{
18 Taking a cue from Do and Gross (2001), I use the terms 'grammar and vocabulary', rather than 'syntax and semantics', to apply to my discussion of diagrams. We are used to the idea that there are separate rules and practices of both grammar and vocabulary, and it is well-understood these gradually change over time and vary over languages and cultures. Shimojima (2001) discusses 7 different versions of the graphic/linguistic pairings, included Goodman's (1976) account of syntax, itself subject to an interesting critique from Elkins (1999) in his account of visual images. Woody (2000) discusses the units of molecular orbital diagrams as members of an 'alphabet'.
} 
for several marriages, with children by each marriage. But there is another typical kinship pattern found in other societies, which can best be diagrammed with diagonal lines in which the children of one's siblings count as one's own. Here the grammar of kinship relations provide the rules of construction and use of the diagram. In general, the grammar is not only important to the depiction, but outlines the allowable manipulation or operations that can be conducted in reasoning with the diagram (and so provides the 'logic' that Klein (1995) points to).

The subject matter of a diagram, as it is developed and used by the community of scientists, feeds constraints and determines possibilities into the operations and vice versa. Once created, the grammar and vocabulary of a diagram do not just depict allowable relations and moves, but also determine some that are not possible. So it is not just the diagram, but their grammars and vocabularies which are developed within a community of use; and these may not always be clearly articulated before they become conventional and unspoken. Thus, these rules of operation and vocabulary are as obvious to those in the community of users in the case of the real space diagram of the pulleys as in they are the artificial space of Marshall's diagrams. In reasoning with the mechanical pulley system diagram, it is the kind of standard parts, and structure of the typical interrelations of the parts, which enable the user of the diagram to figure out what can happen. This involves using the rules of how pulleys work and how the system works to answer questions and solve potential problems about pulley systems by reasoning with the diagram. The rules of how to use the real pulley system are different from the rules of reasoning in the ideal space of a geometric proof; and both are different from the rules of reasoning based upon the grammar and vocabulary of diagrams in artificial space such as Marshall's diagrams. The user of any diagram needs to understand both the grammar and the vocabulary of that system and these will differ between systems. The difference depends not in the nature of the space, but in the subject matters depicted and used in reasoning with the diagram. 
For the business cycle graphs, the grammar may be more clearly defined than the vocabulary. Thus the rules for charting and using the lines on such diagrams must adhere to the rules for reading and using time-series graphs: time is represented on an axis orthogonal to the variables represented, time goes in one direction, and the lines are in a timed relation to each other (even if they do not all match in time, ie are leading or lagging one of the other lines). What exactly these lines refer to, and so how to interpret them is less clear. On the one hand, it is obvious, for they are data taken from various observatories of the economy and treated (as discussed above) to create the lines that reveal the patterns and relations between them. But exactly what the broader inductive space involves is much less obvious, for the community of users interprets these diagrams as 'indicator' diagrams and their interpretation in terms of business cycle ideas, definitions, concepts and theories remains opaque.

In contrast, in the case of the diagrams of supply and demand, the vocabulary and it meanings are rather straightforward to the community as theoretical constructions not empirical ones. The curves have clear meaning to them, and it is clear also what the points on those curves and shifts in the curves represent in terms of the economists' notions of 'laws of supply and demand'. The axes form ordinal scales for the two variables of prices and quantities. It is important that the meanings of the curves have implications for the grammar, that is, for what are allowable shapes and allowable movements of those curves; not all shapes and not all movements are considered possible according to the subject matter represented in the diagram. For example, serious discussions might involve questions as to whether the curves could hit the axes, whether they must be continuous or could be discontinuous, whether they could be wiggly or not, and so forth: issues about the grammar of the diagram. But in the case of the Marshallian diagrams, as with many such theory-driven diagrams in economics, there are elements of the relations and so grammar of usage which are also 
mathematical constructions (such as tangencies to curves) which mean the diagrams depend on a mixed grammar. ${ }^{19}$

The issue here - previously hidden or neglected in worrying about what diagrams are - is the emphasis on the operations that are done on diagrams and how these are constituted, characterised, and restrained. Of course, this is equally relevant to questions about the different operations on representations which are not diagrammatic. This was the starting point for my investigation: namely how decisions about form of representation have implications for the form of reasoning used. As argued in Larkin and Simon (following others, p 68), the differences between representations is not about the notations, but the operations used on them. But the important point for me here is these are not independent. Both have implications for the other, as Chao (2018) shows in his discussion of cases from the history of location theory in geography. I turn to another example in economics to clarify this by looking at examples of different depictions of the same subject matter, using the same vocabulary, but where the diagrams are made in forms that embed conceptual differences between their objects, and require different operations because their use involves different grammars.

Again in the late nineteenth century, three economists developed accounts of the relations that individual people (not groups in the market) had with the goods they sought to consume - the utility relation. These founders of this conceptual and theoretical shift in what is called 'value theory' included, at significant points in their writings, diagrams to motivate their ideas as found in Figure 7 (a, $\underline{\mathbf{b}} \& \underline{\mathbf{c}}$, below). In one of them, William Stanley Jevons (1871), depicted variations in the "intensity of feeling from moment to moment" (p30) as the 'duration' of consumption increases. This curve of feelings of pleasure and pain,

\footnotetext{
19 See Morgan 2012, chapter 2, for an historical account of how economists in developing the Edgeworth box diagram created the vocabulary and grammar of the diagram in ways that used both mathematical and subject matter forms and rules of reasoning.
} 
as directly experienced by the consumer, was transposed into utility space (in Figure 7a), depicting the same kind of intensity (on the vertical axis) and quantity of utility (on the horizontal axis) to be gained from increasing consumption of a commodity (with the area under the curve depicting the whole quantity of utility). The diagram was used to show the feelings of people based on their psychological response as they increased their amount consumed of the good, and to pinpoint the exact point to stop consuming - thus defining the marginal unit of the good. Jevons described and depicted this human behaviour in the 'ideal space' of mathematics using the calculus to define changes in feelings, because for him, the mathematics of his diagram in ideal space mapped the 'real space' of man's physiological and mental experience of utility from consumption.

Figure 7 - Utility Diagrams: 2D diagrams designed to depict theories of utility in ways that enable reasoning.

a) Jevons's utility curve experienced by the individual: 'intensity' on the vertical axis, 'duration' on the horizontal.

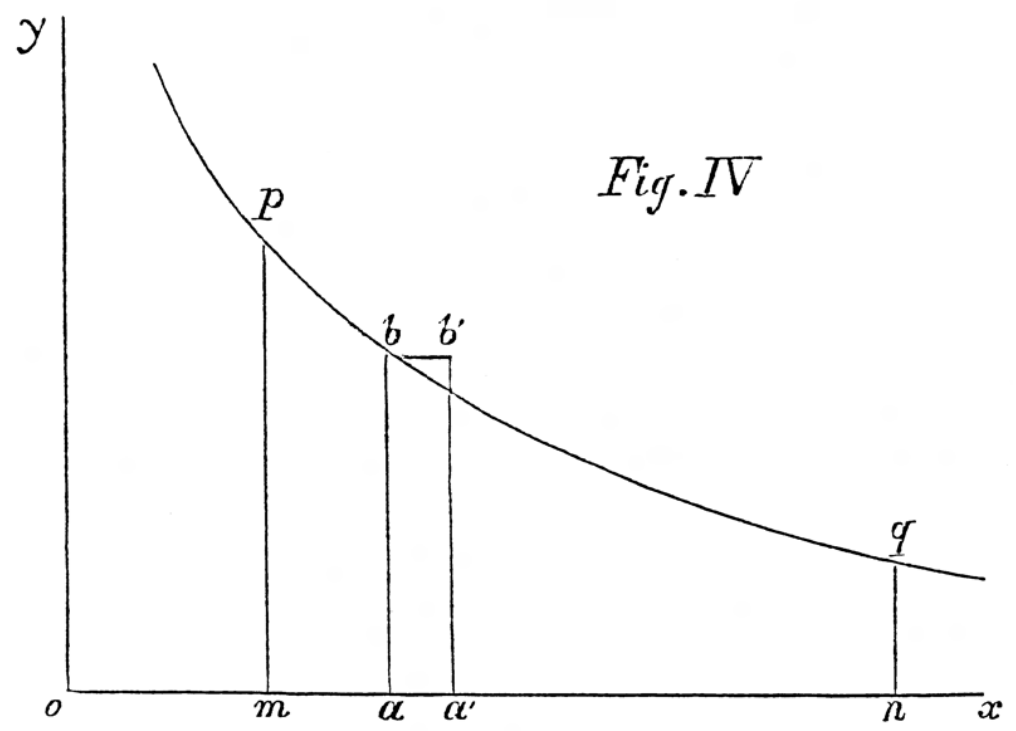

Source: William Stanley Jevons. 1871. Theory of Political Economy. $3^{\text {rd }}$ Edition, 1888. Figure IV, p. 49. London: Macmillan \& Co. 
Another, Carl Menger (1871) produced the 2-D diagram in Figure 7b. This is a particularly interesting example where the rules of usage - its grammar - is not at all self-evident. It looks superficially like a mathematical matrix, but is not. It could be thought of as a 2-D table, but is not quite that either. Its numbers depict not numerical amounts of utility, nor feelings of pleasure and pain from consumption of one good as Jevons' diagram did, but expressed relative equivalent values in satisfying different needs with different goods. The vertical and horizontal dimensions were designed to reflect the gradations of satisfactions of needs in life to be obtained both from consuming more of one good (vertically depicted) and equivalences of each good against a set of different goods (horizontally). Both implied 'axes' use ordinal scales. The point of the diagram is not just to depict the menu of possibilities that the consumer faces, but to use the diagram to make a number of reasoned points. The flexibility of the diagram enabled Menger to depict not only consuming more or less units of the same good (eg, more or less food reasoning downwards), but that these can be interpreted as successive values associated with satisfying different needs by different usages of the same good (for example, satisfactions gained from Good I (water) could be, in descending order of satisfaction, water for drinking, for washing, for cooking, for watering the crops, or for one's dog or horse, etc). More significantly, the diagram is used to demonstrate how equivalence judgements are made by suggesting how a consumer decides at a certain point to stop consuming more units of Good I (to use his example: food) and instead consume their first unit of Good V (tobacco) - namely where the satisfactions to be gained are equal at (ordinal) value 6. These equivalences can be followed by reading the numbers, but are more effectively seen by visual perception because of the alignment of numbers along the diagonals in the $2 \mathrm{D}$ space of the diagram. To know how to use the diagram requires us to understand the grammar of the diagram before we can understand the abstract theses Menger is advancing, but before we can understand those abstract claims about his concept of utility, we need to know the nature of the relationship between the needs of man and the value of different needs satisfied by a good. A succinct understanding of his 
theory requires a sense of how all the goods, needs, and values fit together as in the relationships depicted in the diagram, and which then enable reasoning with those relationships.

Figure 7 - Utility Diagrams: 2D diagrams designed to depict theories of utility in ways that enable reasoning.

b) Menger's utility schedule of satisfactions of needs as experienced by the individual: from goods arrayed horizontally, and each good satisfying different needs arrayed vertically.

$\begin{array}{rccccccccc}\text { THE THEORY } & \text { OF } & \text { VALUE } & & & & & & \\ \text { I } & \text { II } & \text { III } & \text { IV } & \text { V } & \text { VI } & \text { VII } & \text { VIII } & \text { IX } & \text { X } \\ 10 & 9 & 8 & 7 & 6 & 5 & 4 & 3 & 2 & \text { I } \\ 9 & 8 & 7 & 6 & 5 & 4 & 3 & 2 & \text { I } & 0 \\ 8 & 7 & 6 & 5 & 4 & 3 & 2 & 1 & 0 & \\ 7 & 6 & 5 & 4 & 3 & 2 & 1 & 0 & \\ 6 & 5 & 4 & 3 & 2 & 1 & 0 & & \\ 5 & 4 & 3 & 2 & 1 & 0 & & & \\ 4 & 3 & 2 & 1 & 0 & & & & \\ 3 & 2 & 1 & 0 & & & & & \\ 2 & 1 & 0 & & & & & & \end{array}$

Source: Carl Menger. 1871. Principles of Economics. 1950 translated and edited by James Dingwall and Bert F. Hoselitz. p127. New York: The Free Press.

In a third version, J.B. Clark (1899) created the 2-D diagram in Figure 7c depicting the set of different services (utilities), a commodity provides, A through $\mathrm{F}$, with the highest value to the consumer coming from $\mathrm{A}$ and the lowest from $\mathrm{F}$. He argued that the second unit of any commodity used for the same service (eg A) will have negative value (A'), so each different good has a vertical line indicating the positive value of the first unit of the service and its second negative unit (a second overcoat over the first might have negative utility). The letters could also refer to a bundle of different services that consumer might value from the same one commodity. In that case, the sloping line drawn from joining these letters up on the diagram depicts the diminishing amounts of value or utility coming from those different services provided from the same good. For example, imagine the good is a canoe (his example): A could be the service of keeping the person afloat (a service which is satisfied by a certain quality of a 
piece of wood that floats); B could be the power to move across the water; down to F which could be the colour and fittings of the canoe. For Clark, these services were associated with the valuations held by different social groups who would demand those services, for each social group sets or decides its own marginal value for each service, and so sets the price for those services. It is all a bit more complicated than this, but it is clear already that the use of the 2D space, the means of representation, and the practices of reasoning are once again interdependent. And they are very different here in Clark's account from those of Menger and Jevons.

Figure 7 - Utility Diagrams: 2D diagrams designed to depict theories of utility in ways that enable reasoning.

c) Clark's utility graph experienced by the individual as member of a social group: with different degrees of utility vertically, and bundles of different attributes of the good/service horizontally.

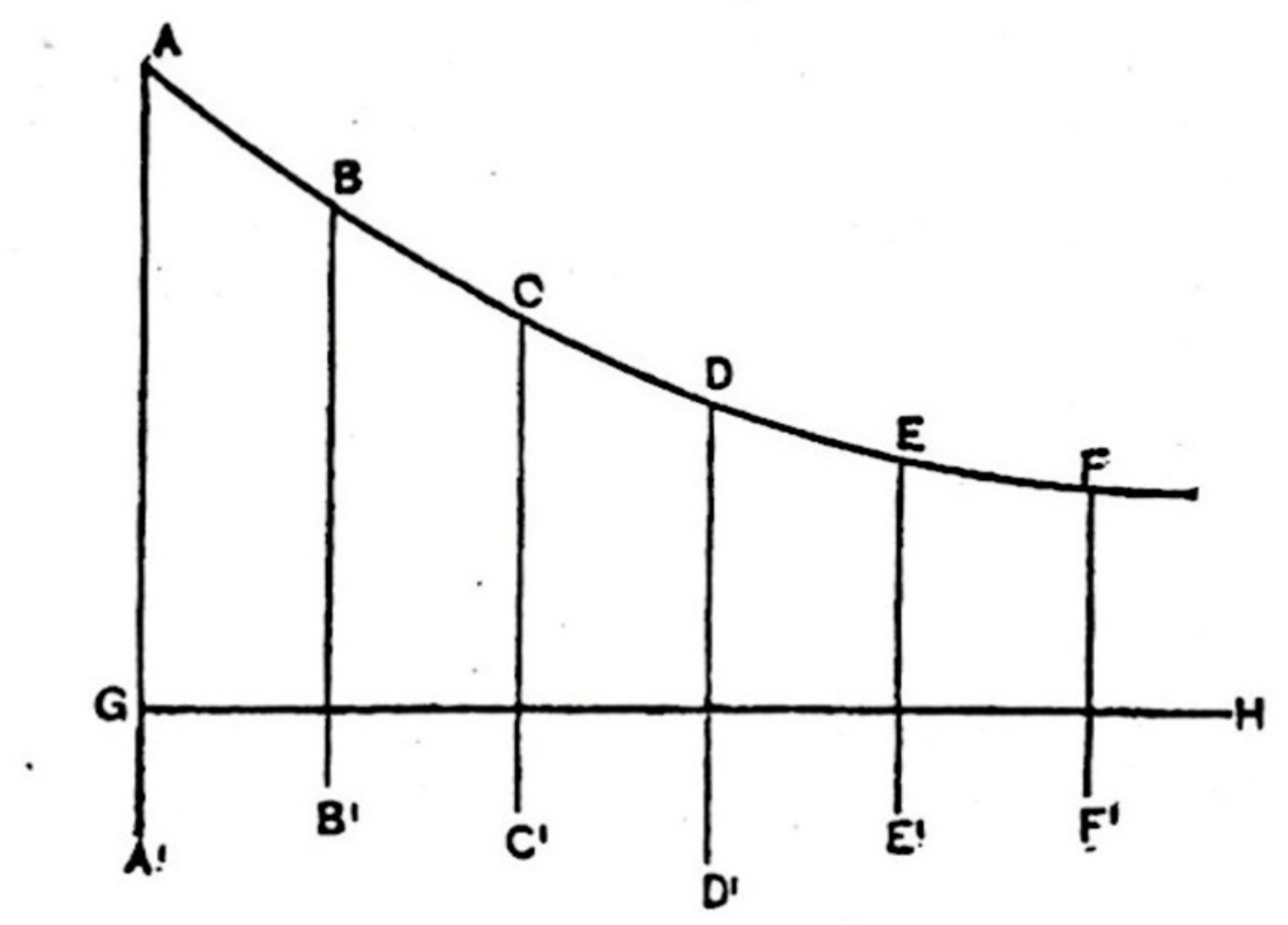

Source: John Bates Clark. 1899. Distribution of Wealth. p232. New York: Macmillan. 
These three different diagrams in Figure 7 are concept-forming visualizations created in conceiving the relations between people and their enjoyment of, or a need for, goods (the concept of utility) explored in diagrams of those relations in 2D space, real or artificial (depending on the scientist involved). Although they all share the notion that the 'marginal unit' is the important one in decision making, they do not share the same diagram, nor a mode of reasoning: the grammar for manipulating and using each diagram is different. This is because, despite bearing the same labels, they do not share the same meanings of utility, the vocabulary has different conceptual connotations across the three. And they each rely in different ways on their diagrams and those spatial arrangements to define and develop their different abstract accounts using a number of elements in that $2 \mathrm{D}$ space. What they also share is using a diagram not just to help define their notions of utility but at the same time to help them to investigate the relations inherent in their concepts. The differences between the three diagrams - and how they can be reasoned with - are critical to an understanding of the difference between their theories.

Again, lest this be considered an example that is peculiar to economics, consider the case of the history of the periodic law and table. Woody (2014 and elsewhere) shows how there were many different depictions of the periodic law, some were diagrams, some were graphs with empirical reference, some were tables-cum graphs, some were 'tables' which, like Menger's, did not fit any standard format. ${ }^{20}$ These objects that represented the periodic table or law were be reasoned with according the grammar and vocabulary of those representations, and their differences were critical to an understanding of the differences in theories about that phenomenon.

\footnotetext{
20 The amazing range of diagrams and other artefacts depicting the periodic law, in its theoretical and empirical counterparts, that appeared over the history of reasoning about the periodic law/table were presented in Andrea Woody's talk at a Pittsburgh workshop on diagrams in 2015; only a small subset are given in Woody (2014). Woody (2000) also provides a informative analysis of the construction, representation, and reasoning associated with different molecular orbital diagrams which parallels some of my analyses in this paper.
} 


\section{Conclusions}

In considering the usage of diagrams in artificial spaces, such as the empirical ones of business cycle evidence and the theoretical experiments with supply and demand curves, there might be a presumption (as I suggested at the start) that the empirical graphs use one kind of logic for statistical thinking (induction), and the supply/demand diagrams use another associated with their mathematical equivalents in algebraic form (deduction). Yet the final examples of utility thinking with diagrams suggests we need to be very cautious in assuming that any particular form of metrics (statistical or mathematical) provide all we need to know to determine the logic of reasoning appropriate for any diagram. The subject matter of a diagram determines not just the vocabulary but the grammar of use which elucidates and determines the operations that can be made on it. Recognising that there will be such vocabularies and grammars enables us to understand scientists' explorations with their diagrams and thus how those activities prove useful to their scientific community.

To illustrate the main point more simply now that it has been made, we can usefully compare diagrams with a familiar subset of diagrams, namely maps. Diagrams come with keys, like map keys: vocabulary labels which are created along with the diagram (see Morgan, 2014 for the importance of this). In economic diagrams, these keys could be labels of empirical materials - such as 'the monthly interest rate' or they could be symbolic forms such as ' $r$ ' referring to the theoretical notion of 'the interest return on capital'. For maps, knowing the keys provides the vocabulary of the map, and enables a user to see what is where. But to use any map to get around the world, users need to know the grammar of the map. The grammar tells the user how the spatial arrangements on the piece of paper are related to the topology and relations depicted in the terrain. Maps come in different forms, and whether the terrain is the flat A-Z one of London streets, or the topological one of the Rocky Mountains, or the hypothetical one of science fiction - each form will have its own grammar just as Figures $\underline{\mathbf{7 a}}, \underline{\mathbf{b}}$, and $\underline{\mathbf{c}}$ do. For maps, as for any diagram, the user needs to 
understand not just how the $2 \mathrm{D}$ space of the particular diagram is organised but how the objects of the diagram relate, and it is this knowledge of the grammar that enables them to use the map for inference and for reasoning. Similarly with a scientific diagram, understanding the grammar enables the user to infer from the diagram or to reason with the diagram about the things represented in the diagram, be they empirical or theoretical materials. Maps are representations of real space, but the same arguments follow in the artificial spaces of diagrams constructed by scientists. A community of scientists visualizing their materials into a diagram in a $2 \mathrm{D}$ artificial space must understand both the grammar and vocabulary of the diagram they have created to use it fruitfully in either the inductive or deductive mode.

Whereas this investigation began with epistemic questions, it appears now that the answers have ontological import. Decisions about diagrams involve decisions not just about what to depict, but how to depict it for use, both of which affect the way that the community thinks about the things depicted. As they develop and use a diagram, those scientists come to understand those subject matters in different ways. Diagrams may begin life to solve epistemological problems, but may have implications for the way those scientists think about their materials and subject matters, and so have ontological consequences. ${ }^{21}$

21 This is a lesser claim than that of world-making that I advanced for the construction of models (2012), but by focussing on form and reasoning, it perhaps becomes a more subtle argument. 


\section{Bibliography}

Blackwell, Alan F. 2001. "Introduction. Thinking with Diagrams." Artificial Intelligence Review 15: 1-3.

Boumans, Marcel. 2016. "Graph-based Inductive Reasoning." Studies in History and Philosophy of Science 59: 1-10.

Chao, Hsiang-Ke. 2018. "Shaping Space Through Diagrams: The Case of the History of Location Theory." Research in the History of Economic Thought and Methodology, 36B: 59-72.

Chao, Hsiang-Ke and Harro Maas. 2017. "Engines of Discovery: Jevons and Marshall on the Method of Graphs and Diagrams." Research in the History of Economic Thought and Methodology 35A: 35-61.

Clark, J.Bates. 1899. Distribution of Wealth. New York: Macmillan.

De Toffoli, Silvia and Valeria Giardino. 2014. "Forms and Roles of Diagrams in Knot Theory." Erkenntnis 79:4: 829-842.

Do, Ellen Yi-Luen and Mark D. Gross. 2001 "Thinking with Diagrams in Architectural Design.” Artificial Intelligence Review 15: 135-49.

Downes, Stephen M. 2012. "How Much Work Do Scientific Images Do?" Spontaneous Generations 6:1: 115-130.

Elkins, James. 1999. The Domain of Images. Ithaca, NY: Cornell University Press.

Giardino, Valeria. 2018. "Tools for Thought: The Case of Mathematics." Endeavour 42: 172-9.

Goodman, Nelson. 1976. Languages of Art. Indianapolis: Hackett.

Hughes, R.I.G. 1997. "Models and Representation." Philosophy of Science 64: S325-336.

Jevons, William Stanley. 1871. Theory of Political Economy. London: Macmillan $\&$ Co.

Klein, Judy. 1995 "The Method of Diagrams and the Black Arts of Inductive Economics." In Measurement, Quantification and Economic Analysis, edited by Ingrid Rima, 98-139. London: Routledge.

Klein, Judy. 1997. Statistical Visions in Time: A History of Time Series Analysis 1662-1938. Cambridge: Cambridge University Press.

Krämer, Sybille. 2016. "Point, Line, Surface as Plane: From Notational Iconicity to Diagrammatology." in Theorizing Images, ed Žarko Paić and Krešimir Purgar, 202-226. Newcastle: Cambridge Scholars Publishing.

Larkin, Jill H. And Herbert A. Simon. 1987. "Why a Diagram is (Sometimes) Worth Ten Thousand Words." Cognitive Science 11: 65-99.

Maas, Harro and Mary S. Morgan. 2002. "Timing History: The Introduction of Graphical Analysis in 19 ${ }^{\text {th }}$ Century British Economics." Revue d'Histoire des Sciences Humaines 7: 97-127.

Menger, C. 1871. Principles of Economics. 1950 translated and edited by James Dingwall and Bert F. Hoselitz. New York: The Free Press.

Morgan, Mary S. 1997. "Searching for Causal Relations in Economic Statistics: Reflections from History." In Causality in Crisis: The New Debate about 
Causal Structures, edited by V. McKim and S. Turner, 47-80. Notre Dame:

University of Notre Dame Press.

Morgan, Mary S. 2002. "Model Experiments and Models in Experiments." In Model-Based Reasoning: Science, Technology, Values, edited by L. Magnani and N.J. Nersessian, 41-58. Dordrecht: Kluwer Academic/Plenum.

Morgan, Mary S. 2012. The World in the Model. Cambridge: Cambridge University Press.

Morgan, Mary S. 2014. "What if? Models, Fact and Fiction in Economics." Journal of the British Academy 2: 231-68.

Morgan, Mary S. 2014a "Re-Situating Knowledge: Generic Strategies and Case Studies." Philosophy of Science 80: 1012-24.

Nikolow, Sybilla. 200. "A.W.F. Crome's Measurements of the 'Strength of the State': Statistical Representations in Central Europe around 1800.” In The Age of Economic Measurement, edited by Judy Klein and Mary S. Morgan, Special Issue, History of Political Economy 33 Supplement: 23-55.

Perini, Laura. 2013. "Diagrams in Biology." The Knowledge Engineering Review 28:3: 273-86.

Priest, Greg. 2018 “Diagramming Evolution: The case of Darwin's Trees.” Endeavour 42: 157-71.

Priest, Greg, De Toffoli, Silvia and Paula Findlen. 2018. "Tools of Reason: The Practice of Scientific Diagramming from Antiquity to the Present." Endeavour 42: 49-59.

Read, Dwight. 2013. "Modeling Cultural Idea Systems: The relationship Between Theory Models and Data Models." In Modelling Practices in the Social and Human Sciences - New Perspectives, edited by Mary S. Morgan, and Till Grüne-Yanoff. Special Issue, Perspectives on Science 21:2: 157-174.

Sheredos, Benjamin, Daniel Burnston, Adele Abrahamsen and William Bechtel. 2013. "Why Do Biologists Use so many Diagrams?" Philosophy of Science 80:5: $931-44$.

Shimojima, Atsushi. 2001. "The graphic-linguistic distinction.” Artificial Intelligence Review 15: 5-27.

Tufte, Edward R. 1983. The Visual Display of Quantitative Information. Cheshire, Conn: Graphics Press.

Tversky, Barbara. 2004 "Semantics, Syntax, and Pragmatics of Graphics." In Language and visualisation, edited by K. Holmqvist \& Y. Ericsson, 138-149. Lund, Sweden: Lund University Press.

Wise, M. Norton. 2017. "On the Narrative Form of Simulations." Studies in the History and Philosophy of Science 62, 74-85.

Woody, Andrea. 2000. "Putting Quantum Mechanics to Work in Chemistry: The Power of Diagrammatic Representation." Philosophy of Science 67: S612-27.

Woody, Andrea. 2014. "Chemistry's Periodic Law. Rethinking Representation and Explanation after the Turn to Practise." In Science After the Practice Turn in the Philosophy of History, and Social Studies of Science, edited by Léna Soler, Sjoerd Zwart, Michael Lynch, and Vincent Israel-Jost, 123-150. New York: Routledge. 